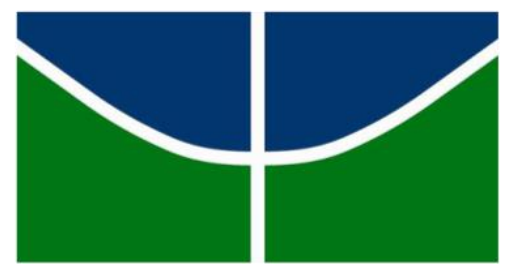

Universidade de Brasília

Instituto de Ciências Biológicas

Programa de Pós-Graduação em Ecologia

ESPÉCIES SEMEADAS E COLONIZADORAS GARANTEM A TRAJETÓRIA SUCESSIONAL DA RESTAURAÇÃO DE FLORESTAS NA BACIA DO ALTO XINGU

Silvia Barbosa Rodrigues

Brasília - DF 2018 


\author{
Universidade de Brasília \\ Instituto de Ciências Biológicas \\ Programa de Pós-Graduação em Ecologia
}

\title{
ESPÉCIES SEMEADAS E COLONIZADORAS GARANTEM A TRAJETÓRIA \\ SUCESSIONAL DA RESTAURAÇÃO DE FLORESTAS NA BACIA DO ALTO \\ XINGU
}

Silvia Barbosa Rodrigues

Orientador: Dr. Daniel Luis Mascia Vieira

Dissertação apresentada ao Departamento
de Ecologia, Instituto de Ciências
Biológicas, Universidade de Brasília,
como requisito parcial do Programa de
Pós-Graduação em Ecologia, para
obtenção do título de Mestre em Ecologia

Brasília, DF

Fevereiro de 2018 


\section{Agradecimentos}

A Deus que me mostra a grandeza do seu amor e da vida sempre nas pequenas coisas.

Aos meus pais, Cláudia e Sérgio, pelo amor e pela força que me dão sempre; à minha avó, Bárbara, pela atenção e carinho e aos meus irmãos, Pedro e Luísa, pelo apoio e companheirismo. Gratidão por estarem sempre comigo e acreditarem em mim.

Mais sinceros agradecimentos ao meu orientador, Daniel Vieira, que confiou na minha capacidade de fazer esse trabalho e me ajudou em todos os momentos.

Ao meu namorado, Raphael, que com sua paciência e franqueza me ajudou academicamente, e me incentivou e confortou quando tudo parecia errado e sem rumo.

A Marina, companheira de campo, de aventuras e desventuras, que esteve comigo ao longo de toda essa caminhada.

Agradeço de maneira especial ao nosso "mateiro", Cléber, grande conhecedor da natureza, que acabou se tornando um grande amigo. Sem dúvidas esse campo não teria acontecido tão bem sem a presença dele.

A todos que nos acolheram no P. A. Brasil Novo. De maneira especial, a Anielly que além de nós ajudar no campo, carregou nossa bateria com a energia maravilhosa e a força que tem.

Aos amigos que a ecologia me trouxe André, Monique, Max, Gustavo, Letícia, Marco Túlio, Pablo, Calixto e Mateus que me incentivaram sempre e contribuíram com discussões e idas ao campo. De maneira especial a Babi que sempre esteve pronta a me dar uma mão.

Aos profissionais do ISA, Gui, Edu, Neto e Júnior, pela paciência de repetir milhares de vezes as informações que precisávamos e por compartilhar conosco os conhecimentos que têm sobre a muvuca. Ao resto da galera do ISA e da Rede de Sementes do Xingu, Rodrigo, Claudinha, Bruna, Héber, Cleu e China que nos receberam tão bem e nos deram todo apoio e logística que necessitamos durante os meses de campo.

Agradeço a todos da Embrapa Cenargen, de maneira especial, os técnicos que nos levaram e ajudaram no campo, Dudu, Juarez e Nilton. Muito grata a Bruno e Chebinha que nos ajudaram com as identificações. E a ao pessoal da sala dos estudantes, Pâmela, Giselle e Victor. De forma especial ao João Carlos pela ajuda com os mapas.

Sou muito grata aos membros da banca examinadora que aceitaram o convite e se disponibilizaram para contribuir com o trabalho.

Agradeço às agencias financiadoras deste projeto, ao CNPq pala concessão da bolsa de mestrado, Rufford Small Grants Foundation, PROEX/CAPES (Projeto 1789/2015) e ao Programa de Pós-Graduação em Ecologia

Por fim, quando nominamos as pessoas as quais somos gratos, podemos esquecer de alguém. Caso isso tenha ocorrido que nesta omissão fique também o meu muito obrigada. 


\section{ESPÉCIES SEMEADAS E COLONIZADORAS GARANTEM A TRAJETÓRIA SUCESSIONAL DA RESTAURAÇÃO DE FLORESTAS NA BACIA DO ALTO XINGU}

\section{Resumo}

Grandes áreas da floresta amazônica já foram desmatadas, inclusive áreas que deveriam ser preservadas, como nascentes e matas ciliares. As nascentes do rio Xingu foram fortemente desmatadas após o processo de ocupação da região na década de 1970, afetando a qualidade da água ao longo deste rio. Diante deste quadro, foi iniciada em 2004 uma mobilização social para recuperação das nascentes do rio Xingu, utilizando como principal método a semeadura direta. A semeadura direta é um método facilmente aplicável em larga escala e com custos menores em relação ao plantio de mudas, mas pode estar associado a filtros ecológicos que restringem o sucesso deste método. Este estudo teve como objetivo verificar as mudanças que ocorrem na composição de espécies de áreas restauradas ao longo de uma cronossequência de 10 anos, avaliar as características das espécies semeadas e colonizadoras que conseguiram se estabelecer nas áreas e investigar se há influência da cobertura de floresta circundante na chegada de espécies colonizadoras. O estudo foi realizado em 72 áreas de preservação permanente restauradas via semeadura direta ao longo de um gradiente latitudinal na margem leste da bacia do Alto Xingu no estado do Mato Grosso. Ao longo da cronossequência as comunidades passaram de dominadas por uma única espécie pioneira, Mabea fistulifera, para uma distribuição mais equilibrada. Nestas florestas, espécies pioneiras de crescimento rápido como Tachigali vulgaris, Enterolobium timbouva e Anadenanthera cf. peregrina formaram o dossel, enquanto espécies de crescimento mais lento, como M. fistulifera, Hymenae coubaril, Dipteryx alata, Myracrodruon urundeuva e Astronium fraxinifolium apresentaram indivíduos no sub-dossel e na classe regenerante. Verificou-se assim uma estratificação das florestas que demonstrou o sucesso da semeadura direta como um método de restauração. Ao todo foram amostradas 67 espécies colonizadoras, em 39 das 72 áreas estudadas. Não foi encontrada relação entre a cobertura de floresta e o número de espécies colonizadoras. O conjunto das espécies semeadas tem mais sementes ortodoxas e anemocóricas, geralmente disponíveis na estação seca, alguns meses antes do plantio, que zoocóricas e recalcitrantes, mais abundantes nas florestas de referência. No entanto, espécies colonizadoras representam as características funcionais encontradas nas espécies das florestas da região, sugerindo que os filtros ecológicos associados à semeadura direta não se mantém na paisagem estudada, cuja cobertura florestal média é de $20,8 \%$ em um raio de $120 \mathrm{~m}$. Pesquisas futuras sobre técnicas que aumentem o sucesso no estabelecimento e o número de espécies de sucesso na semeadura direta são recomendadas para a ampliação de uso deste método em áreas em que os custos das sementes são maiores e que não haja cobertura florestal na paisagem.

Palavras-chave: Restauração ecológica, semeadura direta, composição de espécies, atributos funcionais, Floresta Estacional Perenifólia. 


\title{
SEEDED AND COLONIZING SPECIES GUARANTEE RESTORATION SUCCESSIONAL TRAJECTORY OF FORESTS IN XINGU UPPER BASIN FORESTS
}

\begin{abstract}
A wide expanse of the Amazon forest has been deforested, including areas that should have been protected such as headwaters and riparian forests. The headwaters of the Xingu river were heavily cleared following the region's occupation in the 1970s, and this affected water quality along the water course. In this context, a social mobilization was started in 2004 for the recovery of the Xingu river's headwaters, using direct seeding as the main method of ecological restoration. Direct seeding is a method easily implemented at large scales and lower costs compared to seedling plantings, but it is associated to ecological filters that restrict the method's success. This study aimed to assess the changes in species composition that take place in restored areas over a 10-year chronosequence, evaluate the attributes of seeded and colonizer species that were able to establish themselves in the areas, and investigate whether colonizer arrival is influenced by the amount of surrounding forest. The study was conducted in 72 permanent preservation areas restored via direct seeding along a latitudinal gradient, at the east margin of the Upper Xingu Basin, state of Mato Grosso, Brazil. Over the chronosequence, plant communities went from being dominated by a single pioneer species, Mabea fistulifera, to a more even species distribution. In these forests, rapid growth pioneer species formed the canopy, such as Tachigali vulgaris, Enterolobium timbouva, and Anadenanthera cf. peregrina, while slow growth species were present both in the understory and in the regenerating class, such as M. fistulifera, Hymenae coubaril, Dipteryx alata, Myracrodruon urundeuva, and Astronium fraxinifolium. Thus, we verified the forests stratification, which demonstrated the success of using direct seeding as a restoration method. A total of 67 colonizer species were sampled, in 39 of the 72 studied sites. We found no relationship between forest cover and the number of colonizer species. The group of seeded species has more orthodox and wind dispersed seeds - usually available during the dry season, some months before plantings - than animal dispersed and recalcitrant seeds, more abundant in baseline forest. However, colonizer species represent the functionality traits found in the regional forests, suggesting that the ecological filters associated to direct seeding do not persevere in the landscape studied, in which the average forest landscape cover was $20.8 \%$ in a 120 m radius. Future research to investigate techniques that can promote an increase in the establishment success and the number of success species in direct seeding are recommended to expand the use of this method in areas where the seed costs are higher and with no forest cover in the landscape.
\end{abstract}

Key-words: Ecological restoration; direct seeding, species composition, functional traits, Evergreen Seasonal Forest. 


\section{Sumário}

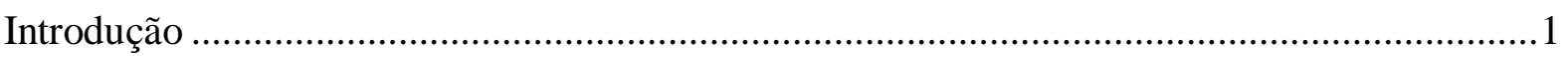

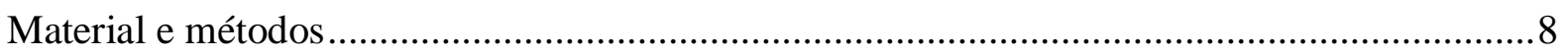

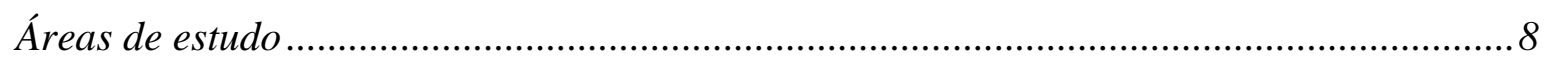

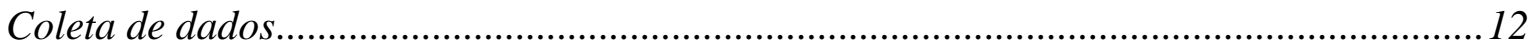

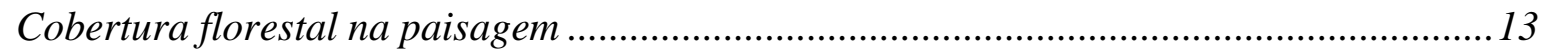

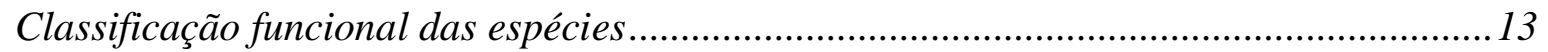

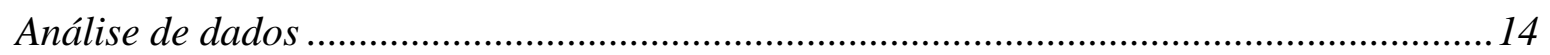

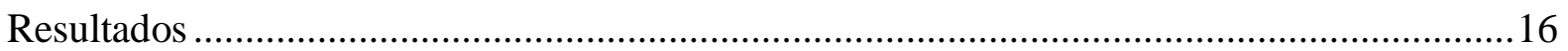

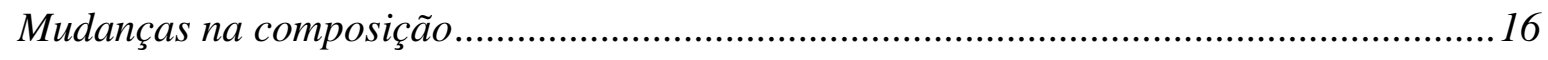

Características funcionais de espécies semeadas, colonizadoras e de floresta de referência

Efeito da paisagem na colonização de espécies ...................................................................24

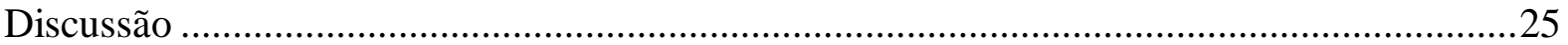

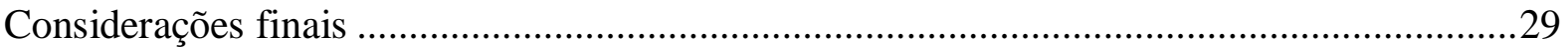

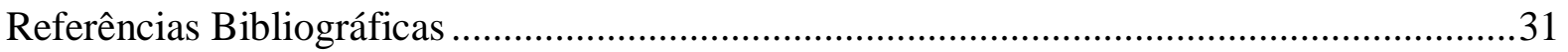

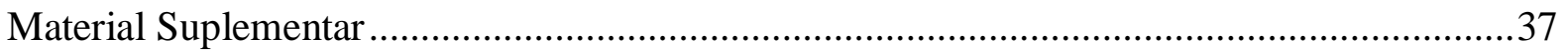




\section{Lista Figuras e Tabelas}

Figura 1 Processos de dinâmica da vegetação associados com os estágios de sucessão secundária em clareiras em florestas tropicais (Adaptado de Chazdon 2008).

Figura 2 Localização das 72 áreas de estudo no nordeste do estado do Mato Grosso. Os pontos amarelos indicam as localizações das áreas estudadas.

Figura 3 Parcelas instaladas nas 72 áreas restauradas por semeadura direta na bacia do rio Xingu. Na parcela de $500 \mathrm{~m}^{2}$ foram amostrados indivíduos classe dossel $(\mathrm{H}>1,30 \mathrm{~m}$ e DAP $\geq$ $10 \mathrm{~cm}$ ); na parcela de $100 \mathrm{~m}^{2}$ individuos classe sub-dossel $(\mathrm{H}>1,30 \mathrm{~m}$ e DAP < $10 \mathrm{~cm})$; e na parcela de $25 \mathrm{~m}^{2}$ indivíduos classe regenerante $(0,30 \leq \mathrm{H} \leq 1,30 \mathrm{~m})$.

Figura 4 As dez espécies mais abundantes em áreas restauradas por semeadura direta em classes de idade: (a) áreas com 1 - 3 anos, (b) áreas com $4-6$ anos, e (c) áreas com 7 - 10 anos. Nomes com asterisco são espécies encontradas em florestas referencias da região (Ivanauskas et al., 2003; Kunz et al., 2008; Marimon et al., 2001). .18

Figura 5 Ordenação (NMDS) da composição separada por estratos e idade das áreas. Letras são a abreviação dos nomes das 13 espécies mais abundantes ao longo da cronosequência. AP: A. cf. peregrina; AFR: A. fraxinifolia; BO: B. orellana; BP: B. pachyphylla; BR: B. rufa; DA: D. alata; ET: E. timbouva; HC: H. courbaril; JC: J. cuspidifolia; MF: M. fistulifera; MU: M. urundeuva; SA: S. amara; TV: T. vulgaris. Estresse $=0,15$.

Figura 6 Classificação das espécies semeadas, colonizadoras e da floresta referência quanto a tolerância à dessecação (a), síndrome de dispersão (b) e classe sucessional (c). Espécies da floresta referência foram obtidas em Stefanello et al. (2010).

Figura 7 Relação entre a idade e o número de espécies colonizadoras por parcelas (amostragem em $500 \mathrm{~m}^{2}$ para indivíduos $\mathrm{H}>1,30 \mathrm{~m}$ e DAP $\geq 10 \mathrm{~cm} ; 100 \mathrm{~m}^{2}$ para indivíduos $\mathrm{H}>1,30 \mathrm{~m}$ e DAP < $10 \mathrm{~cm}$; e $25 \mathrm{~m}^{2}$ para indivíduos $0,3 \leq \mathrm{H} \leq 1,3 \mathrm{~m}$ ). A linha mostra a relação prevista e a área sombreada indicam intervalo de confiança de 95\%. Os pontos foram deslocados horizontalmente para evitar sobreposição das áreas. .25

Tabela 1 Resultado das análises dos modelos lineares generalizados (GLMs) do efeito das variáveis preditoras (idade, buffer 120, 200 e 500 m) no número de espécies colonizadoras. Em negrito GLM com variáveis significativas. 


\section{Material Suplementar}

Tabela S1 Relação de espécies utilizadas em plantios de semeadura direta para restauração de áreas degradadas na bacia do alto Xingu, MT. Elaborada a partir da lista utilizada em 17 plantios 37

Tabela S2 Espécies amostradas em áreas restauradas por semeadura direta na bacia do Alto Xingu, MT, indicando frequência de parcelas em que cada espécie ocorreu. .41 


\section{Introdução}

A floresta amazônica está presente em nove países da américa latina e representa metade das florestas tropicais do mundo, onde se encontram as maiores áreas florestais ainda intactas (Corlett \& Primack, 2008). No entanto, esta floresta é a que sofre maior taxa de desmatamento no mundo (Hansen et al., 2008). A área desmatada entre 1990 e 2007, nos nove países, foi de 63,8 milhões de hectares (Peres et al., 2010). As florestas tropicais são ameaçadas por diferentes atividades humanas, como por exemplo, exploração madeireira, caça, fogo e expansão agropecuária (Corlett \& Primack, 2008; Peres et al., 2010). Sessenta e seis por cento da floresta amazônica está no território brasileiro, o que representa cerca de $28 \%$ da floresta tropical do mundo (FAO, 2015). Contudo, com a crescente expansão do agronegócio, da mineração e de projetos de infraestrutura, como criação de novas estradas e construção de hidrelétricas, mais de 75 milhões de hectares de florestas já foram desmatados no país (Greenpeace, 2016). As fronteiras do sul e leste da Amazônia são as mais afetadas e tornaramse conhecidas como "arco do desmatamento", região responsável por 85\% do desmatamento neste bioma (Fearnside, 2005).

Nesta região encontra-se o rio Xingu, entre os estados de Mato Grosso e Pará, considerado símbolo de diversidade biológica e cultural brasileira, que forma um corredor de “diversidade socioambiental" abrangendo 20 terras indígenas, 10 unidades de conservação e se estende por 28 milhões de hectares (Velasquez et al., 2010). No estado do Mato Grosso localizam-se as nascentes e cabeceiras do rio Xingu, formando a bacia do Alto Xingu. Região que compreende 17,7 milhões de hectares com paisagens únicas por estar na zona de transição entre o bioma Amazônico e Cerrado, onde a fitofisionomia predominante é Floresta Estacional Perenifólia (Ivanauskas et al., 2004; Villas-Boas, 2012). O processo de ocupação que se iniciou na década 1970 teve o intuito de trazer desenvolvimento econômico à região e com estas florestas foram desmatadas para implantação de pastagens e áreas de cultivo de grãos. De 1970 
até 2010 foram desmatados 37\% do território da bacia do Alto Xingu, sendo que as áreas de nascentes e matas ciliares desmatadas somavam 315 mil hectares em 2009 (Velasquez et al. 2010; Villas-Boas 2012). Uma das consequências deste desmatamento foi a deterioração da qualidade da água redução na abundância dos peixes do rio Xingu, afetando os povos indígenas que ali habitam. Em 1994 os povos indígenas do Xingu buscaram apoio do Instituto Socioambiental (ISA) para iniciar um processo de diálogo com a população da bacia do Alto Xingu. Desta maneira, em 2004, com a participação e mobilização de povos indígenas, comunidades ribeirinhas, produtores rurais, organizações governamentais e não governamentais, foi lançada a campanha "Y Ikatu Xingu" (salve a água boa do Xingu) com o intuito de proteger e recuperar as nascentes do Rio Xingu. Ainda são poucos os projetos que como este, tem o objetivo de recuperar áreas degradadas na região amazônica. Uma recente iniciativa foi anunciada na abertura do festival de música "Rock in Rio", em setembro de 2017, que tem como meta a recuperação de uma área de quase 30 mil hectares até 2023. Este é considerado o maior projeto de reflorestamento que já aconteceu para a recuperação de florestas na Amazônia. No entanto, recuperaria apenas 5\% do desmatamento que ocorre na região todos os anos (Moura, 2018). A tendência é que a situação mude e mais projetos de recuperação comecem a acontecer com a criação da Aliança pela Restauração na Amazônia, que atuará como catalisadora de ações que promovam a restauração neste bioma (Aliança, 2017).

Para que seja possível a recuperação de ecossistemas desmatados são necessários métodos de restauração eficazes, viáveis economicamente, aplicáveis em larga escala e que envolvam os donos de terras e as comunidades locais (Holl, 2017). A restauração ecológica é definida como a recuperação assistida de um ecossistema que foi degradado ou destruído (SER, 2004). Existem diversas métodos de restauração ativa como transferência do banco de sementes (Sampaio et al., 2007), translocação da camada superficial do solo (Ferreira \& Vieira, 
2017), nucleação (Corbin \& Holl, 2012) e semeadura direta (Campos-Filho et al. 2013), mas o método mais utilizado para restauração de florestas é o plantio de mudas (Holl, 2002; Palma \& Laurance, 2015; Rodrigues et al., 2009). Neste método, pode ser utilizado desde uma a algumas espécies de crescimento rápido, até diversas espécies de diferentes classes sucessionais, com o objetivo de sombrear e excluir gramíneas exóticas, atrair dispersores de espécies tardias, e melhorar condições microclimáticas e do solo, podendo assim acelerar o processo de sucessão (Rodrigues et al., 2009). No entanto, muitas vezes o resultado alcançado pelo plantio de mudas é a formação de um dossel contínuo e um habitat homogêneo (Corbin \& Holl, 2012), que consegue excluir a gramínea exótica, mas nem sempre há formação de estratos, criando um bosque sem regenerantes embaixo do dossel (Sansevero et al., 2011). A semeadura direta é uma técnica alternativa ao plantio de mudas em que há crescente interesse por ser de rápida implementação em larga escala e economicamente mais viável (Campos-Filho et al. 2013; Engel \& Parrotta 2001).

A semeadura direta consiste em plantar as sementes diretamente no solo de áreas a serem restauradas. Neste método pode ser utilizado uma mistura de espécies com diferentes ciclos de vida, que vai de meses a anos. Espécies de vida de ciclo de vida curto, geralmente arbustos, vão garantir o recobrimento do solo em poucos meses, diminuindo a cobertura de competidoras exóticas e facilitando o estabelecimento de plântulas de espécies arbóreas (Campos-Filho et al. 2013; Silva et al. 2015). Devido à grande quantidade de sementes utilizada, a densidade inicial de recrutas nas áreas restauradas pela semeadura direta tende a ser alta, assemelhando-se ao processo de sucessão secundária em áreas em regeneração (Barton \& McElhinny, 2012; Campos-Filho et al., 2013; Sovu et al., 2010). A utilização de espécies de diferentes classes sucessionais na mistura utilizada na semeadura pode caracterizar duas vantagens potenciais de seu uso: formar uma floresta estratificada e garantir a trajetória sucessional durante as primeiras décadas de restauração. Outra possível vantagem deste 
método, é a antecipação de ações corretivas. Um estudo feito por Meli e colaboradores (2017) aponta que em um mês é possível determinar se houve sucesso ou insucesso na semeadura direta, podendo ser adotadas medidas para alcançar densidades desejadas através de plantios de mudas ou semeadura direta. No entanto, a eficácia deste método ainda precisa ser avaliada com estudos de longa duração.

Existem diversos filtros ecológicos associados ao método da semeadura direta que acaba limitando as espécies utilizadas. Os primeiros filtros são impostos já no processo de coleta e armazenamento destas sementes, dado que espécies de árvores com sementes recalcitrantes, geralmente zoocóricas, não podem ser armazenadas. Os filtros ecológicos associados à semeadura direta apontados na literatura são a baixa porcentagem de germinação, especialmente de espécies com sementes pequenas (Camargo et al., 2002), alta predação de sementes (Guarino \& Scariot, 2014), forte competição de plântulas estabelecidas com gramíneas (Doust et al., 2006) e baixas taxas de sobrevivência em relação aos plantios de mudas (Palma \& Laurance, 2015). Outra possível desvantagem do método pode ser decorrente de condições climáticas adversas, como veranicos, que podem ocasionar morte de plântulas recém germinadas e comprometer o desenvolvimento da floresta (Silva et al., 2015; Vieira \& Scariot, 2006). Apesar de ser um método que vem sendo testado (Aguirre et al., 2015; BonillaMoheno \& Holl, 2010; Florentine et al., 2013; Guarino \& Scariot, 2014), ainda são necessárias informações sobre a performance das espécies e grupos funcionais que se estabelecem através da semeadura direta (Meli et al., 2017).

Os diversos métodos de restauração ecológica têm como objetivo iniciar ou acelerar o processo de sucessão secundária em áreas degradadas (Vieira et al., 2009). Quando florestas sofrem algum tipo de distúrbio, sejam estes naturais ou antrópicos, o processo de sucessão secundária acontece, recuperando a comunidade de plantas e as propriedades do ecossistema (Chazdon, 2012). O processo sucessional em grandes clareiras de florestas tropicais segue uma 
trajetória de recuperação que se inicia com a dominância de espécies pioneiras de crescimento rápido e dispersão ampla. Estas espécies são aos poucos substituídas por outras de classes sucessionais tardias. À medida que o tempo passa a complexidade estrutural e funcional da floresta secundária aumenta (Chazdon, 2012). No entanto, em áreas onde houve distúrbios antrópicos, fatores como o histórico de uso da terra, a condição de fertilidade do solo, a presença de vegetação competidora, o esgotamento do banco de sementes e a ausência de fonte de propágulos podem dificultar o processo de sucessão, ou fazer com que trajetórias alternativas aconteçam, tornando mais lento o processo de recuperação (Mesquita et al., 2001). Estabelecer estágios para as trajetórias sucessionais permite identificar quais os processos ecológicos envolvidos em cada fase para que a recuperação da floresta aconteça (Chazdon, 2012). Chazdon (2008) propôs três estágios e identificou os processos de dinâmica da vegetação que ocorrem durante a sucessão secundária em clareiras em florestas tropicais (Quadro 1). Os processos identificados na Figura 1 podem contribuir também para avaliar o sucesso de projetos de restauração e para melhoria dos métodos utilizados. Viani e colaboradores (2017) sugeriram que, para avaliar o grau de sucesso do projeto de restauração de florestas tropicais, seja verificada a ocorrência de duas fases, encontradas no Figura 1. A primeira é o desenvolvimento do dossel com uma cobertura mínima de 70\%; a segunda é a presença de estratos, isto é, indivíduos com diferentes classes de tamanho, que irão garantir a trajetória sucessional (Viani et al., 2017). 

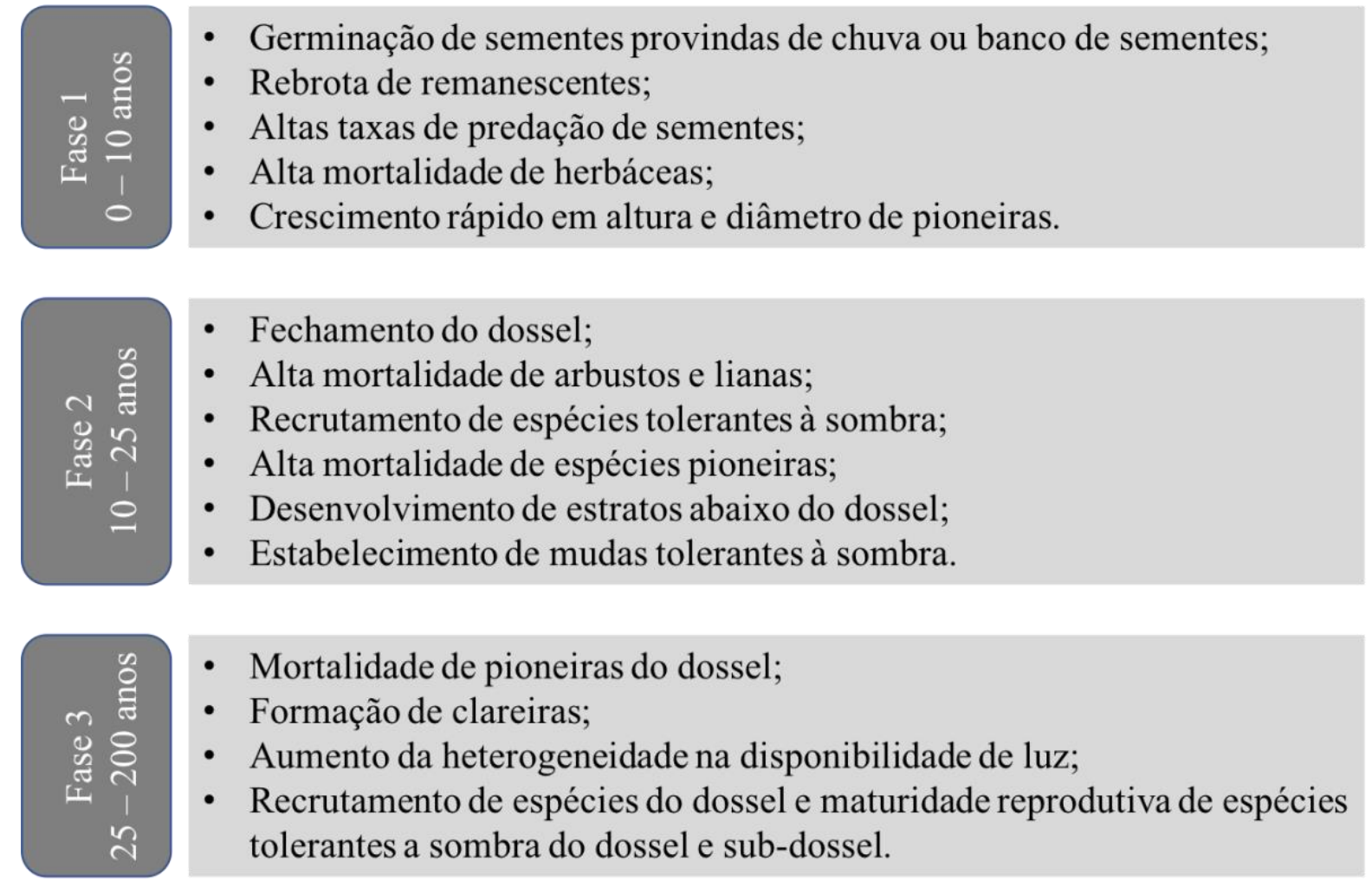

Figura 1 Processos de dinâmica da vegetação associados com os estágios de sucessão secundária em clareiras em florestas tropicais (Adaptado de Chazdon 2008).

Projetos de restauração de florestas tropicais começaram a acontecer nos últimos 25 anos (Holl, 2002) e muitas perguntas ainda precisam ser respondidas. Considerando que nos últimos anos a semeadura direta vem sendo difundida como alternativa mais barata e aplicável em larga escala, é importante entender o desenvolvimento das florestas em processo de restauração onde este método foi implementado. As pesquisas feitas com este método já investigaram diferentes questões, mas sempre relacionadas ao estabelecimento das espécies: emergência e sobrevivência de espécies com sementes de traços funcionais diferentes (BonillaMoheno \& Holl, 2010; Camargo et al., 2002; Engel \& Parrotta, 2001; Ferreira et al., 2009; Silva \& Vieira, 2017); uso de fertilizantes e plantas companheiras (Silva et al., 2015); efeito da densidade de sementes plantadas (Meli et al., 2017); viabilidade de sementes após armazenamento (Lima et al., 2008) e diferentes preparos do solo (Hooper et al., 2002). No 
entanto, poucos são os estudos que investigaram a trajetória inicial da composição de espécies após alguns anos da semeadura direta (Florentine et al., 2013; Parrotta \& Knowles, 1999). Essa fase da trajetória é importante, pois se existem filtros ecológicos associados a semeadura direta, que selecionam de forma severa as espécies estabelecidas, as áreas restauradas teriam uma composição viciada e possivelmente determinante para a trajetória sucessional.

Na bacia do Alto Xingu, plantios de restauração que utilizam a semeadura direta foram e ainda estão sendo implementados para cumprir a legislação que determina a recuperação de florestas ciliares nas áreas de preservação permanente (APP, Brasil, 2012). Na região, quase 5 mil hectares foram restaurados por semeadura direta, utilizando 175 toneladas de sementes em uma década (ISA, 2017). Este projeto oferece uma oportunidade única para entender a restauração por semeadura direta em larga escala, em áreas com diferentes composições de paisagens e idades. Neste contexto, este estudo teve o objetivo de responder às seguintes perguntas:

1. Como a composição de espécies mudou ao longo da cronossequência de 10 anos?

Ao responder esta pergunta, confirma-se ou não a argumentação de que a composição de espécies com diferentes ciclos de vida garante a cobertura da vegetação ao longo dos primeiros anos de restauração, sem retrocesso ao estado alternativo de capins exóticos.

2. Quais as espécies que se estabeleceram por semeadura direta e quais as características das sementes destas espécies?

A hipótese é que a semeadura direta está associada a filtros ecológicos para sementes recalcitrantes, geralmente associadas a espécies zoocóricas. Este possível viés na composição de espécies pode resultar em uma comunidade diferente da floresta madura original.

3. Quais as características das espécies que se estabeleceram, mas não foram semeadas? Quanto a paisagem contribui para a chegada destas novas espécies? 
Ao verificar se há colonização de espécies não semeadas, típicas das florestas maduras da região, pressupõe-se a redução dos filtros associados a semeadura direta. Se há variação na colonização de acordo com a paisagem, isso implica em manejo diferenciado de enriquecimento a depender da paisagem.

\section{Material e métodos}

\section{Áreas de estudo}

As áreas estudadas encontram-se no nordeste do estado do Mato Grosso (Figura 2). Esta região foi alvo da campanha "Y Ikatu Xingu", que, através da semeadura direta, iniciou a recuperação de mais de 5 mil hectares de áreas degradadas na região Xingu-Araguaia. O solo da região é caracterizado pela baixa disponibilidade de nutrientes e alto teor de alumínio, com predominância de latossolo vermelho e amarelo. O clima é do tipo AW (Köppen 1948), com duas estações bem definidas: verão úmido (Outubro a Março) e inverno seco (Abril a Setembro). A precipitação apresenta uma variação de $500 \mathrm{~mm}$ ao longo da bacia. No sul desta bacia chove $1.400 \mathrm{~mm}$ por ano e a seca se estende por um período de seis meses; no norte da bacia chove até $1.900 \mathrm{~mm}$ por ano, com um período de seca de quatro meses (Ivanauskas et al., 2008). A região é uma zona de transição entre o bioma Cerrado e Amazônico, com formação florestal predominante classificada como Floresta Estacional Perenifólia que apesar de estar na área de contato entre floresta ombrófila e cerrado, apresenta características próprias (Ivanauskas et al., 2008). Estas florestas apresentam dossel irregular entre 10 - $20 \mathrm{~m}$ de altura, área basal média $21 \mathrm{~m}^{2} / \mathrm{ha}$ e densidade média de 546 indivíduos/hectare (indivíduos com diâmetro a altura do peito $>10 \mathrm{~cm}$; Ivanauskas et al. 2004). Quando comparadas com florestas de outras bacias hidrográficas amazônicas, o número de espécies arbóreas na região é baixo, variando entre 51 - 66 espécies em um hectare (Ivanauskas et al. 2004). Estudos fitossociológicos na região mostraram grande variação na representatividade das espécies encontradas, Amaioua guianensis Aubl., Aspidosperma discolor A. DC., Hirtella racemosa 
Lam., Ocotea leucoxylon (Sw.) Laness. Sloanea eichleri K. Schum. e Xylopia amazonica R.E. Fr., Chaetocarpus echinocarpus (Baill.) Ducke, Guatteria schomburgkiana Mart., Ocotea guianensis Aubl., Ouratea discophora Ducke, Protium pilosissimum Engl. e Trattinnickia glaziovii Swart podem ser consideradas espécies frequentes na Floresta Estacional Perenifólia (Kunz et al., 2009). Na região há situação de concentração fundiária, onde $71 \%$ de sua extensão é propriedade privada com predominância de propriedades rurais médias e grandes (Velasquez et al., 2010). Terras indígenas representam $24 \%$ do território, unidades de conservação $1 \%$ e assentamentos rurais 4\% (Velasquez et al., 2010). As principais atividades econômicas desenvolvidas na região Xingu Araguaia são a pecuária, produção de soja e exploração madeireira.

As áreas estudadas foram implantadas pela campanha "Y Ikatu Xingu" entre os anos de 2006 e 2015, foram selecionadas 72 áreas de áreas de preservação permanentes (APP) restauradas através da semeadura direta considerando-se abranger ao máximo as idades de plantio, variação em precipitação e sazonalidade, uso anterior, desde que houvesse relativamente fácil acesso. Foram amostradas seis áreas com um ano, três áreas com dois anos, seis com três anos, 11 com quatro anos, sete com cinco anos, 14 com seis anos, sete com sete anos, oito com oito anos, quatro com nove anos e seis áreas com 10 anos. As áreas encontramse ao longo da margem direita da bacia do Alto Xingu, mas X áreas estão localizadas na bacia do Araguaia. A área mais ao norte localiza-se no município de Santa Cruz do Xingu e a área mais ao sul no município de Nova Xavantina, distantes cerca de $540 \mathrm{~km}$ em linha reta. Nas áreas restauradas estudadas a preparação do solo foi realizada através de gradagem, para descompactação, nivelamento do terreno e controle de gramíneas exóticas antes do plantio. Quando necessário, foi feito também controle químico do capim com glifosato, antes do plantio, e depois do plantio com herbicida seletivo para folhas estreitas (Campos-Filho et al., 2013b). Foram obtidas as listas de espécies semeadas em 17 áreas, a partir das quais foi 
produzida uma lista única de espécies utilizadas para que fosse possível uma comparação entre o que foi plantado e estabelecido. A mistura de sementes plantadas na semeadura direta, chamada de "muvuca" pela campanha, foi semelhante entre as áreas, utilizando-se cerca de 30 sementes $\mathrm{m}^{-2}$, sendo 10 sementes $\mathrm{m}^{-2}$ de espécies leguminosas (uma semente de Cajanus cajan (L.) Millspaugh, três de Canavalia ensiformia (L.) DC e seis de Crotalaria spectabilis Roth) e 20 sementes $\mathrm{m}^{-2}$ de árvores. De maneira geral, a proporção de sementes de árvores pioneiras e não pioneiras foi de 1:1, e o número de espécies semeadas foi de 15 - 20 pioneiras e 50 - 60 espécies não pioneiras (Guerin et al., 2015). 


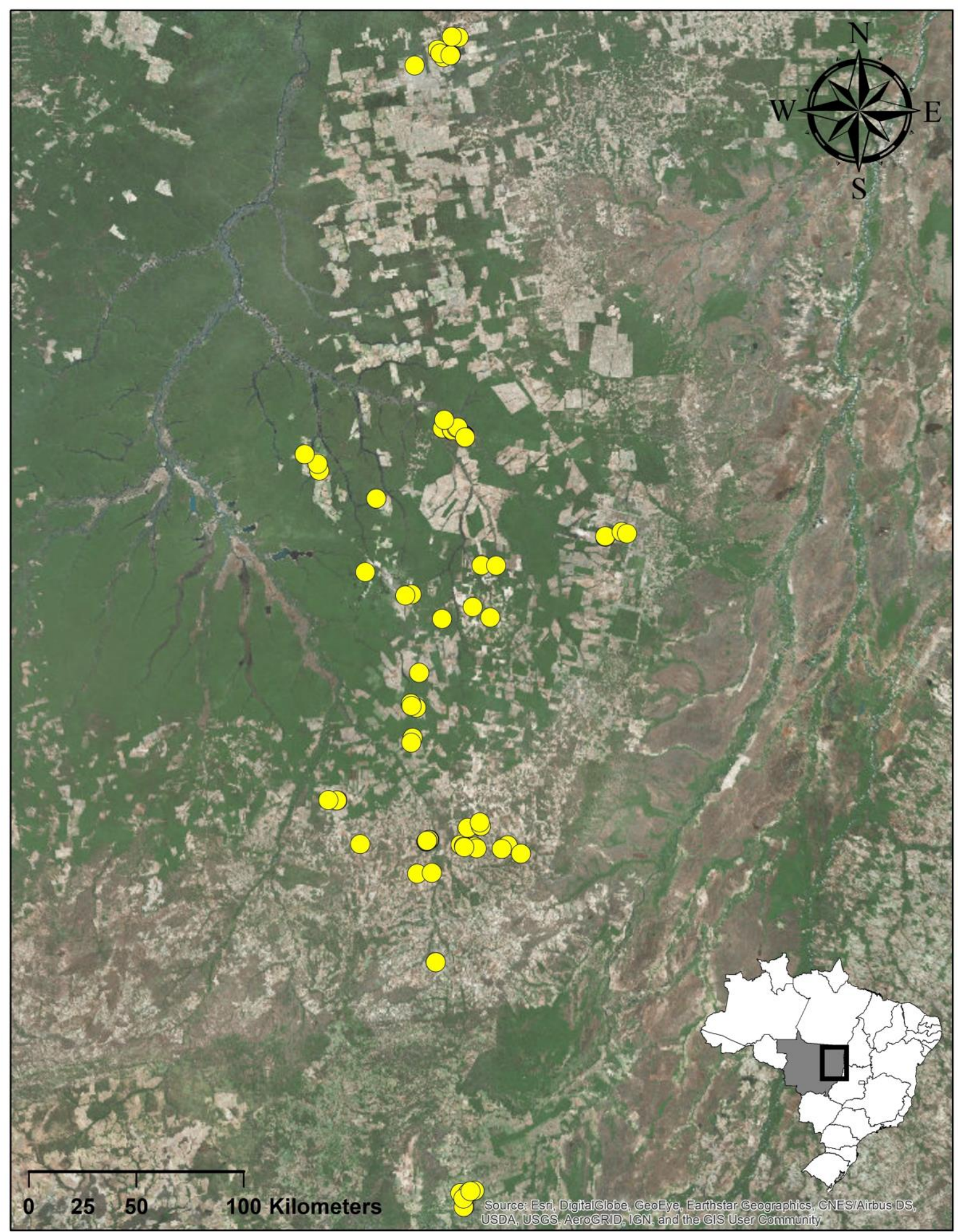

Figura 2 Localização das 72 áreas de estudo no nordeste do estado do Mato Grosso. Os pontos amarelos indicam as localizações das áreas estudadas.. 


\section{Coleta de dados}

Em cada uma das 72 áreas restauradas por semeadura direta, foi alocada uma parcela de $500 \mathrm{~m}^{2}(50 \mathrm{~m} \times 10 \mathrm{~m})$, evitando proximidade das bordas das áreas amostradas. As áreas tinham 30 m de largura por comprimentos variáveis, uma vez que esses plantios atendem à legislação de APP. No centro de cada parcela de $500 \mathrm{~m}^{2}$ foram alocadas duas subparcelas, uma de $100 \mathrm{~m}^{2}$ (50 m x $2 \mathrm{~m}$ ) e outra de $25 \mathrm{~m}^{2}$ (50 m x 0,5 m; Figura 3). Em $500 \mathrm{~m}^{2}$ foram amostrados todos os indivíduos arbóreos com altura $>1,30 \mathrm{~m}$ e DAP (diâmetro altura do peito) $\geq 10 \mathrm{~cm}$ (classe dossel). Na subparcela de $100 \mathrm{~m}^{2}$ foram amostrados indivíduos com altura > 1,30 m e DAP $<10 \mathrm{~cm}$ (classe sub-dossel). Por fim, na área de $25 \mathrm{~m}^{2}$ foram amostrados indivíduos com altura entre 0,30 m e 1,30 m (classe regenerante). Além da coleta dos dados de altura, DAP ou DAS (diâmetro altura do solo - para os indivíduos classe regenerante), todos os indivíduos arbóreos amostrados foram numerados e identificados até nível de espécie. Lianas e palmeiras não foram amostradas. Quando a identificação das espécies em campo não foi possível, foram feitas exsicatas para posterior comparação com dados da literatura e de herbário. O material coletado foi depositado no acervo do Herbário da Embrapa Recursos Genéticos e Biotecnologia (CEN).

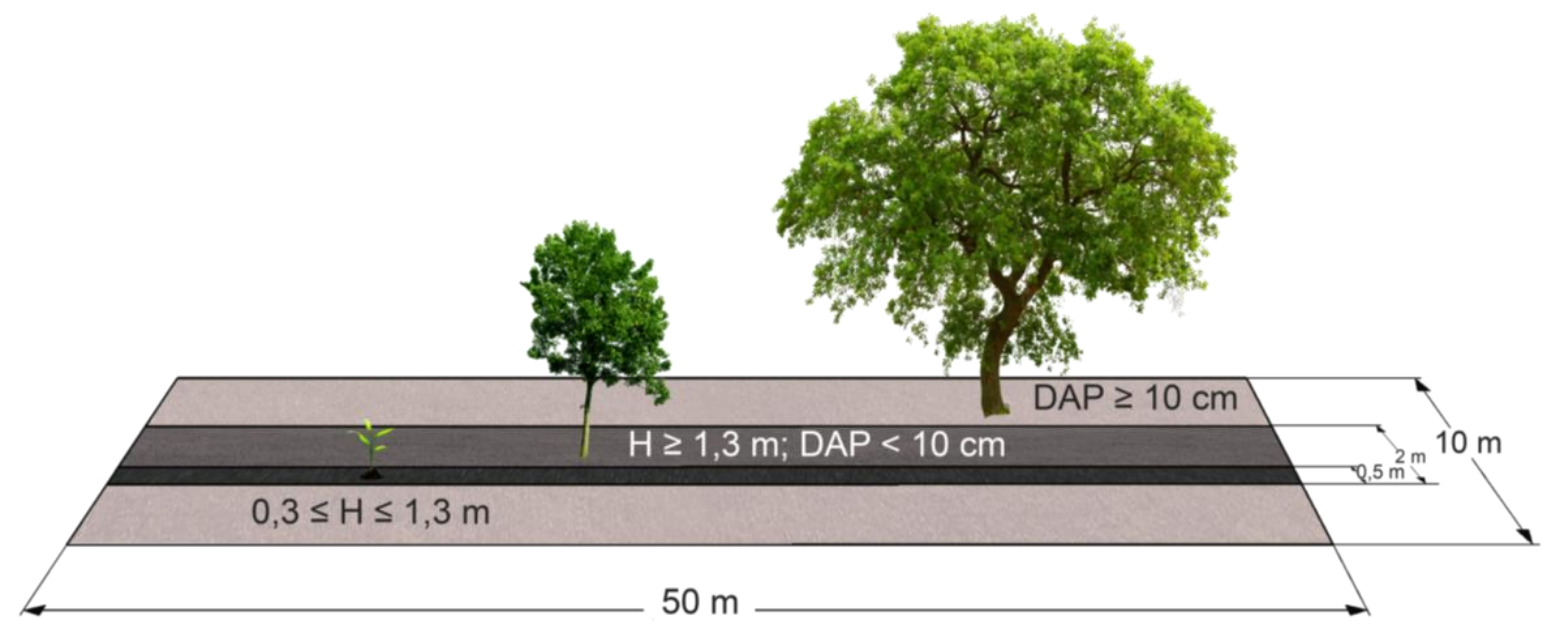

Figura 3 Parcelas instaladas nas 72 áreas restauradas por semeadura direta na bacia do rio Xingu. Na parcela de $500 \mathrm{~m}^{2}$ foram amostrados indivíduos classe dossel $(\mathrm{H}>1,30 \mathrm{~m}$ e DAP $\geq$ 
$10 \mathrm{~cm})$; na parcela de $100 \mathrm{~m}^{2}$ individuos classe sub-dossel $(\mathrm{H}>1,30 \mathrm{~m}$ e DAP $<10 \mathrm{~cm})$; e na parcela de $25 \mathrm{~m}^{2}$ indivíduos classe regenerante $(0,3 \leq \mathrm{H} \leq 1,3 \mathrm{~m})$.

\section{Cobertura florestal na paisagem}

Para verificar se houve influência da cobertura de floresta na colonização por espécies não plantadas, foi determinada a área de florestas maduras em um buffer de 120, 200 e $500 \mathrm{~m}$ (Holl et al., 2017; Jakovac et al., 2015; Rocha et al., 2016) ao redor de cada parcela estudada. Para isto, foi utilizada a classificação da cobertura e uso da terra do Projeto MapBiomas (MapBiomas, n.d.).

\section{Classificação funcional das espécies}

As espécies semeadas (Tabela S1) foram classificadas como "sem sucesso" quando não amostradas e "estabelecidas" quando amostradas. Além disso, espécies amostradas que não constavam na lista de semeadas foram classificadas como "colonizadoras". Espécies colonizadoras são aquelas que surgiram e se estabeleceram nas áreas após a semeadura, ou que rebrotaram de regenerantes remanescentes. Pelo aspecto visual das plantas, a rebrota ocorreu em menor proporção que as colonizadoras por sementes, mas não houve diferenciação entre estes dois tipos, agrupando-se todas como colonizadoras.

Com o intuito de comparar atributos funcionais das espécies semeadas e colonizadoras com aquelas existentes em uma floresta madura da região (chamada de floresta referência), foram utilizados dados fitossociológicos de uma Floresta Estacional Perenifólia (Stefanello et al. 2009). Foram obtidas informações na literatura sobre três atributos funcionais: tolerância à dessecação da semente, síndrome de dispersão e classe sucessional. Foi encontrada informação sobre tolerância da semente à dessecação para 105 espécies das 157 espécies amostradas, para 43 das 61 espécies semeadas sem sucesso e para 23 das 67 espécies da floresta referência (Conserva et al., 2013; Costa, 2009; Cruz et al., 2016; Delgado \& Barbedo, 2007; Garwood \& Lighton, 1990; Mayrinck et al., 2016; Mori et al., 2012; Santos, 2013; Sena et al., 2016). Em 
relação à tolerância à dessecação, as espécies foram classificadas em ortodoxas (sementes que podem ser desidratadas a níveis baixos de umidade e armazenadas em ambientes de baixas temperaturas), recalcitrantes (sementes que não podem ser desidratadas abaixo de um determinado grau de umidade, sem que ocorram danos fisiológicos) e intermediárias. Quanto à síndrome de dispersão, as espécies foram classificadas como anemocóricas (dispersão pelo vento), autocóricas (dispersão sem auxílio de agentes externos) e zoocóricas (dispersão por animais). Tal informação foi encontrada para 155 espécies amostradas (semeadas estabelecidas + colonizadoras), e para todas as semeadas sem sucesso e da floresta de referência (Stefanello et al., 2009). Por fim, a classe sucessional das espécies seguiu a classificação de Swaine e Whitmore (1988) que separam árvores tropicais em dois grupos: pioneiras (sementes que precisam de luz para germinar e plântulas que precisam de luz para estabelecimento e crescimento) e não pioneiras (sementes que conseguem germinar na sombra e plântulas que conseguem se estabelecer e sobreviver na sombra). Foi encontrada esta informação para 117 espécies amostradas, 43 espécies semeadas sem sucesso e 43 espécies da floresta referência (Castro, 2012; Gouveia et al., 2011; Mori et al., 2012; Neto, 2012).

\section{Análise de dados}

\section{Como a composição de espécies mudou ao longo da cronossequência de 10 anos?}

Para entender como a composição de espécies mudou ao longo dos 10 anos, foram estabelecidas três classes de idade para as áreas: (1) um a três anos $(\mathrm{n}=15),(2)$ quatro a seis $(\mathrm{n}=32)$, e (3) sete a 10 anos $(\mathrm{n}=25)$. Este agrupamento foi necessário, pois a quantidade de áreas em algumas idades foi baixa, gerando picos abruptos na densidade das espécies causados por uma área apenas. Foram comparadas as densidades das 10 espécies mais abundantes entre as classes de idade, considerando as classes de tamanho dos indivíduos (dossel, sub-dossel e regenerante) de cada espécie. Buscou-se em estudos de florística em florestas maduras da região (Ivanauskas et al., 2003; Kunz et al., 2008; Marimon et al., 2001) a presença das dez espécies mais abundantes amostradas neste estudo, com o intuito de verificar se as espécies bem-sucedidas na semeadura direta são encontradas nessas florestas. 
Para verificar se houve diferença na composição de espécies entre classes de tamanhos dos indivíduos (dossel, sub-dossel e regenerantes), que representa a estratificação da floresta, foi feita uma análise de ordenação. Primeiramente, foi calculada a abundância relativa de indivíduos de cada espécie em relação ao número total de indivíduos amostrados em cada classe, após a retirada de espécies com menos de dois indivíduos. A partir destes dados, foi calculado o índice de similaridade de Bray-Curtis entre dossel, sub-dossel e regenerantes, e a matriz resultante foi utilizada no Escalonamento Multimenssional Não Métrico (NMDS; Quinn \& Keough 2002).

Quais as espécies que se estabeleceram por semeadura direta e quais as características das sementes destas espécies? Quais as características das espécies colonizadoras?

Para entender se a coleta e o armazenamento filtram as espécies que são utilizadas na semeadura direta, as proporções das espécies de cada característica funcional foi comparada entre espécies semeadas e espécies de floresta de referência. Para verificar se houve filtro ambiental pós-plantio, comparou-se espécies semeadas sem sucesso com espécies semeadas estabelecidas. Para saber se espécies colonizadoras reduzem os filtros associados a semeadura direta e apresentam características semelhantes à floresta de referência, comparou-se espécies colonizadoras com espécies semeadas estabelecidas e com espécies da floresta de referência. Essas comparações foram feitas através de testes de Qui-quadrado $\left(\chi^{2}\right)$, considerando $\alpha=0,05$ (Zar, 2010). Todas as análises foram realizadas utilizando-se o software $\mathrm{R}$ ( $\mathrm{R}$ Core Team 2013).

Quanto a paisagem contribuiu para a chegada destas novas espécies?

Para verificar o efeito das variáveis preditoras (cobertura de floresta em um raio de 120, 200 e 500 m e idade desde o plantio) no número de espécies colonizadoras, foram utilizados modelos lineares generalizados (GLMs). A família de distribuição utilizada foi binomial negativa, família que mais se ajusta a distribuição dos dados. 


\section{Resultados}

Nas 72 áreas de semeadura direta estudadas foram amostrados 5.170 indivíduos, pertencentes a 157 espécies distribuídas em 101 gêneros de 42 famílias (Tabela S2). Vinte e duas espécies foram identificadas somente até nível de gênero, nove até nível de família e seis espécies não foram identificadas. Fabaceae foi a família com maior número de espécies (46), seguida por Myrtaceae (10). Fabaceae também teve o maior número de indivíduos (1.896), seguida por Euphorbiaceae (1.372). Quarenta e cinco por cento das espécies foram amostradas com até dois indivíduos. A mesma proporção foi amostrada em apenas uma das 72 parcelas.

\section{Mudanças na composição}

Em áreas com idade entre 1 e 3 anos $(n=15)$ foram amostrados em média 3.546 ind/ha na classe de regenerantes, 2.393 ind/ha na classe sub-dossel e 2 ind/ha na classe dossel. Mabea fistulifera foi a espécie dominante, com $63 \%$ da área basal e $33 \%$ dos indivíduos. Neste intervalo de idade foram amostradas 44 espécies, das quais 12 tiveram apenas um indivíduo.

Em áreas entre 4 e 6 anos $(n=32)$ foram amostrados em média 4.800 ind/ha na classe de regenerantes, $5.940 \mathrm{ind} / \mathrm{ha}$ na classe sub-dossel e $144 \mathrm{ind} /$ ha na classe dossel. Tachigali vulgaris teve $28 \%$ da área basal, seguida por $M$. fistulifera com $21 \%$. No entanto, M. fistulifera representou $31 \%$ dos indivíduos e $28 \%$ dos regenerantes desta classe de idade. Neste intervalo de idade foram amostradas 107 espécies, 34 tiveram apenas um indivíduo. Treze espécies apresentaram indivíduos em todas as classes de tamanho

Em áreas entre 7 e 10 anos $(n=25)$ foram amostrados em média 6.112 ind/ha na classe de regenerantes, $5.760 \mathrm{ind} / \mathrm{ha}$ na classe sub-dossel e $270 \mathrm{ind} / \mathrm{ha}$ na classe dossel. Seis espécies, T. vulgaris, M. fistulifera, E. timbouva, A. occidentale, H. courbaril e A. cf. peregrina, foram responsáveis por $52 \%$ da área basal nestas parcelas. Foram encontradas 110 espécies, sendo que 32 espécies tiveram apenas um indivíduo. As dez espécies mais abundantes tiveram indivíduos em todas as classes de tamanho (Figura 4). Mabea fistulifera apresentou $20 \%$ de todos os regenerantes nesta classe de idade. 
Ao longo da cronossequência, as comunidades passaram de forte dominância de uma espécie pioneira para uma distribuição mais equilibrada. Com o avanço da idade, as áreas restauradas se estratificaram, com indivíduos em diferentes classes de tamanho. Dentre as espécies mais abundantes, $M$. fistulifera, $H$. courbaril, D. alata e $T$. vulgaris foram encontradas em florestas maduras da região. Estas quatro espécies, juntamente com E. timbouva são encontradas em todas as classes de idade. 


\section{1 a 3 anos}

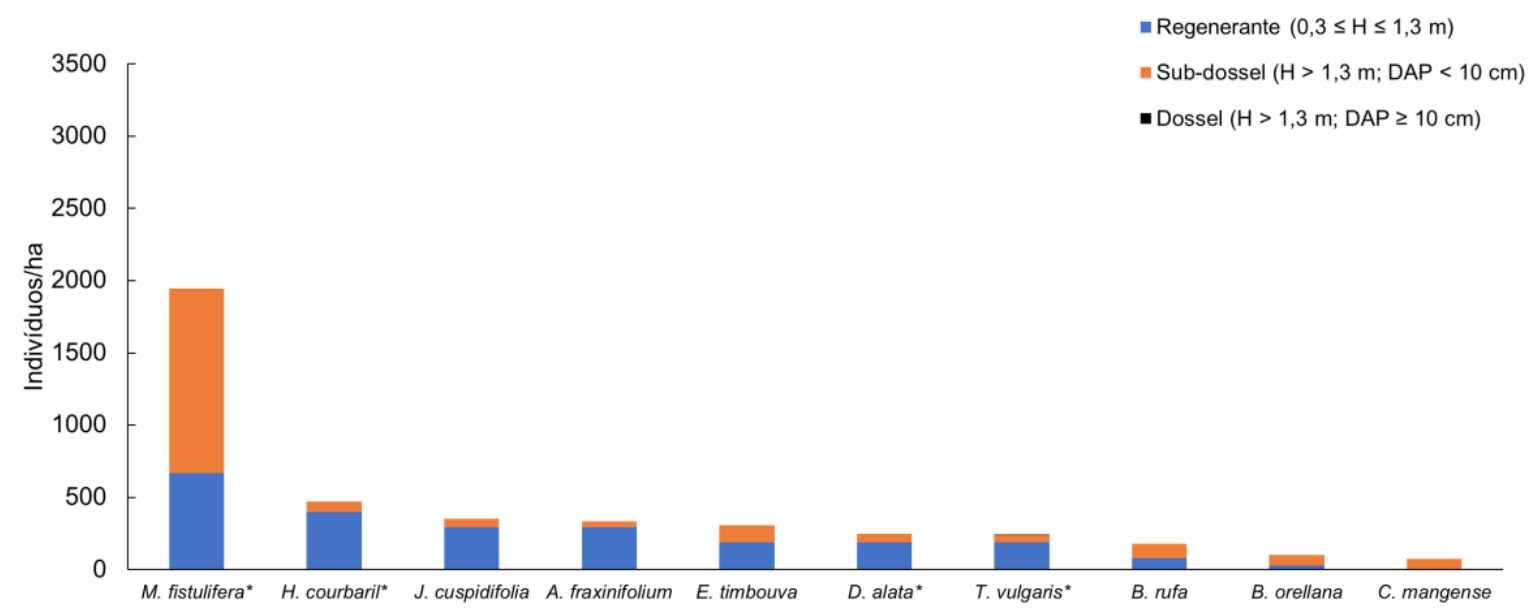

\section{4 a 6 anos}

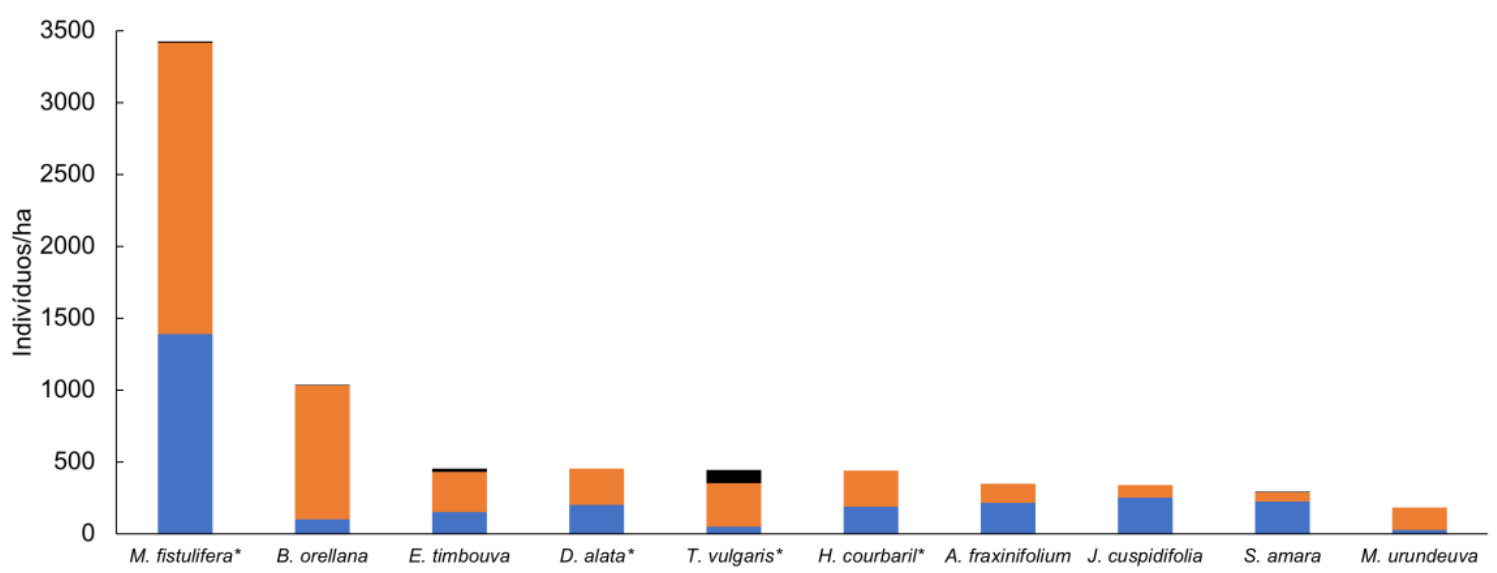

\section{7 a 10 anos}

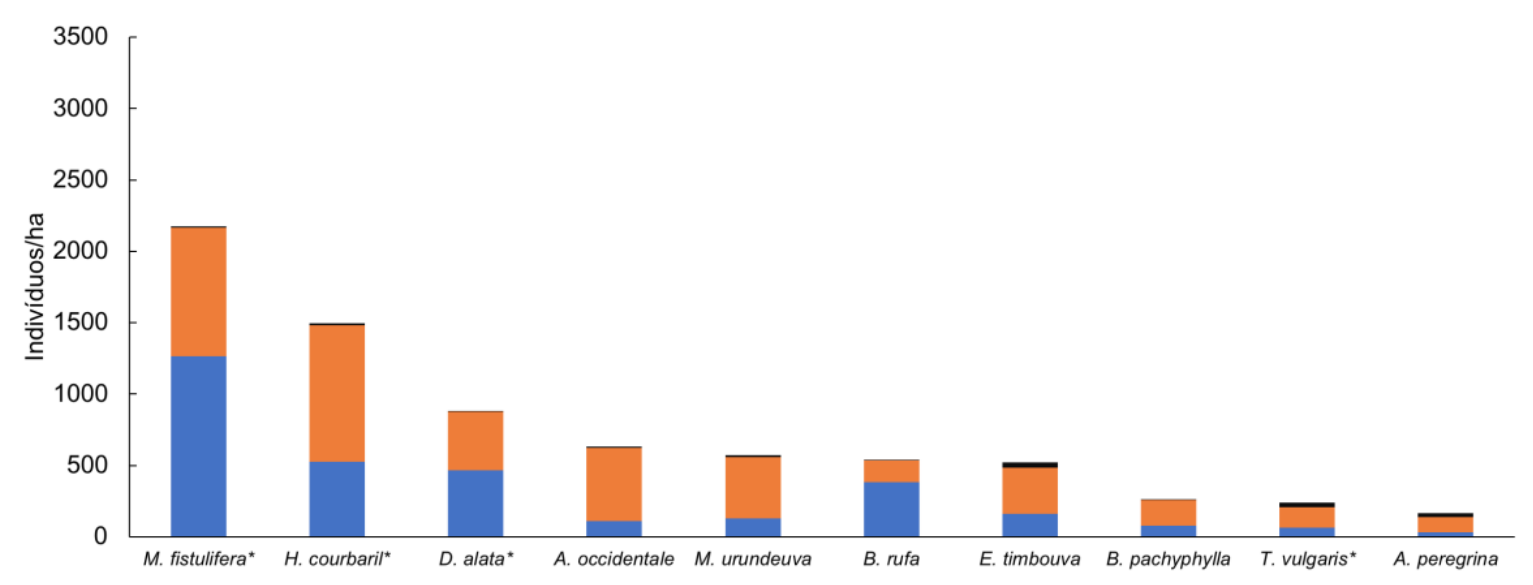

Figura 4 As dez espécies mais abundantes em áreas restauradas por semeadura direta em classes de idade: (a) áreas com $1-3$ anos $(\mathrm{n}=15)$, (b) áreas com $4-6$ anos $(\mathrm{n}=32)$, e (c) áreas com 7 - 10 anos $(n=25)$. Nomes com asterisco são espécies encontradas em florestas referencias da região (Ivanauskas et al., 2003; Kunz et al., 2008; Marimon et al., 2001). 
Das 157 espécies amostradas, 32 foram amostradas com indivíduos nas três classes de tamanho (dossel, sub-dossel e regenerante), A classe dossel foi a que apresentou menor número de espécies exclusivas (3 espécies), e compartilhou 9 espécies com a classe sub-dossel e apenas uma espécie com a classe regenerante. A classe sub-dossel apresentou 42 espécies exclusivas e compartilhou 47 espécies com a classe regenerante. A classe regenerante apresentou 23 espécies exclusivas. Na análise de ordenação da composição separada por estratos e idades, houve um gradiente na mudança da composição de espécies do dossel de áreas com idades entre $4-6$ e 7 - 10 anos (NMDS 1 negativo e NMDS 2 positivo) e árvores de sub-dossel e regenerantes de áreas com idades entre $4-6$ e 7 - 10 anos (NMDS 1 positivo e NMDS 2 negativo; Figura 5), demonstrando troca de espécies entre o dossel e os estratos inferiores. Já áreas com idade entre 1 - 3 anos não apresentaram indivíduos na classe dossel, e tiveram posição mais central no eixo NMDS 1 (Figura 5).

Dentre as espécies mais abundantes, T. vulgaris, E. timbouva e A. cf. peregrina têm crescimento rápido e por isto tiveram grande representatividade de indivíduos na classe dossel (NMDS 1 negativo e NMDS 2 positivo; Figura 5). As demais espécies abundantes têm crescimento mais lento, assim apresentaram valores na ordenação mais próximos de indivíduos nas classes sub-dossel e regenerantes. Portanto, as espécies mais abundantes são encontradas nas diferentes classes de tamanho de indivíduos, conferindo estratificação às áreas estudadas. 


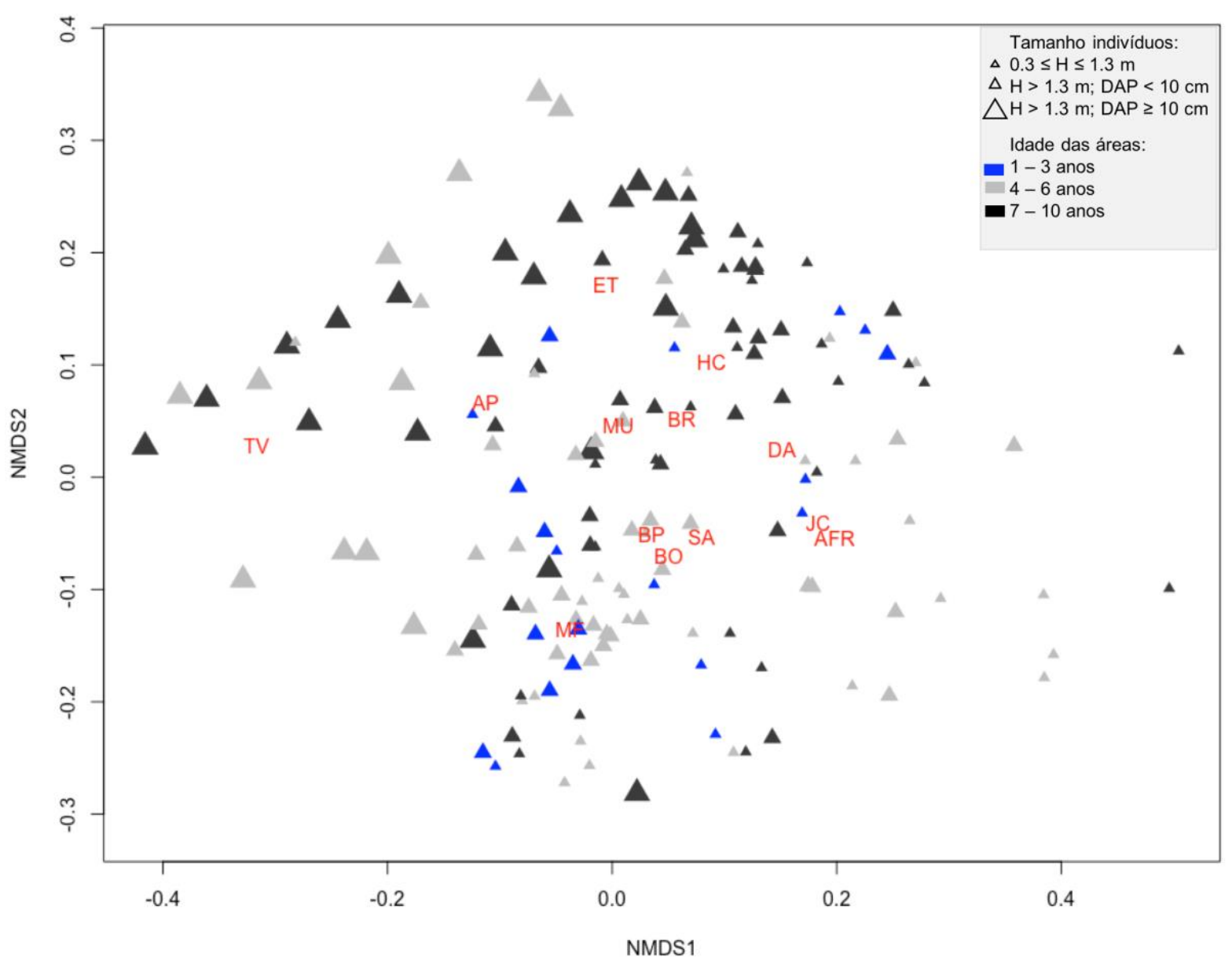

Figura 5 Ordenação (NMDS) da composição separada por estratos e idade das áreas. Letras são a abreviação dos nomes das 13 espécies mais abundantes ao longo da cronosequência. AP: A. cf. peregrina; AFR: A. fraxinifolia; BO: B. orellana; BP: B. pachyphylla; BR: B. rufa; DA: D. alata; ET: E. timbouva; HC: H. courbaril; JC: J. cuspidifolia; MF: M. fistulifera; MU: M. urundeuva; SA: S. amara; TV: T. vulgaris. Estresse =0,15.

\section{Características funcionais de espécies semeadas, colonizadoras e de floresta de referência}

As espécies semeadas e estabelecidas representam $62 \%$ do total de espécies semeadas. O número de indivíduos de espécies semeadas estabelecidas foi de 4.811 (93\% do total amostrado). A espécie semeada estabelecida com maior número de indivíduos foi $M$. fistulifera, apresentando 1.309 (27\%) indivíduos, e cada uma das outras 89 espécies contribuiu com menos de $10 \%$ de indivíduos. As oito espécies mais frequentes, amostradas em mais de 40\% das áreas estudadas, foram M. fistulifera (amostrada em $76 \%$ das áreas), $H$. courbaril (76\%), D. alata (69\%), E. timbouva (60\%), T. vulgaris (50\%), A. occidental (44\%), B. orellana 
(40\%) e A. fraxinifolium (40\%). Os $7 \%$ dos indivíduos restantes pertenceram a espécies colonizadoras (não semeadas), correspondendo a 42\% do total de 157 espécies amostradas.

A espécie colonizadora com maior número de indivíduos foi Vismia brasiliensis, com $84(23 \%)$ indivíduos, e cada uma das outras 66 espécies contribuiu com menos de $10 \%$ dos indivíduos de espécies colonizadoras. A espécie colonizadora amostrada em maior número de áreas foi S. guianensis, em 5,5\% das áreas. Foram encontradas espécies colonizadoras em todas as classes de tamanho. No entanto, apenas duas espécies foram amostradas em todas as classes de tamanho em uma mesma área (Matayba sp. e Maytenus robusta), sugerindo que estas espécies estão recrutando nestas áreas.

A frequência das características funcionais foi diferente entre as espécies semeadas (semeadas sem sucesso + estabelecidas) e as espécies da floresta de referência para os três atributos considerados (Figura 6): tolerância à dessecação $\left(\chi^{2}=7,7 ; p=0,005\right)$, síndrome de dispersão $\left(\chi^{2}=16,6 ; p<0,001\right)$, classe sucessional $\left(\chi^{2}=3,7 ; p=0,053\right)$. O grupo das espécies semeadas teve maior frequência de espécies ortodoxas e pioneiras, e menor frequência de zoocóricas do que a floresta referência. Entre as espécies semeadas estabelecidas e sem sucesso, houve diferença de frequência dos atributos funcionais somente em relação à tolerância a dessecação $\left(\chi^{2}=7,5 ; p=0,006\right)$, enquanto não houve diferença para síndrome de dispersão $\left(\chi^{2}=2,6 ; p=0,260\right)$ e classe sucessional $\left(\chi^{2}=0,5 ; p=0,42\right)$, de modo que as espécies estabelecidas tiveram maior frequência de sementes ortodoxas do que as sem sucesso (Figura 6a). As espécies colonizadoras não diferiram das espécies da floresta referência em relação a tolerância à dessecação $\left(\chi^{2}=0,0 ; p=1\right)$ e a síndrome de dispersão $\left(\chi^{2}=2,8 ; p=\right.$ 0,242; Figura 6a e b). No entanto, houve diferença em relação a classe sucessional entre espécies colonizadoras e espécies da floresta de referência $\left(\chi^{2}=6,9 ; p=0,008\right)$, sendo que há maior frequência de espécies pioneiras entre as colonizadoras (Figura 6c). Por fim, espécies colonizadoras foram diferentes das espécies semeadas estabelecidas em relação a tolerância a 
dessecação $\left(\chi^{2}=17,7 ; p<0,001\right)$ e à síndrome de dispersão $\left(\chi^{2}=18,7 ; p<0,001\right)$, e não foi encontrada diferença em relação à classe sucessional $\left(\chi^{2}=0,6 ; p=0,426\right)$. 
a

90

80

70

ఏ 60

$\stackrel{\mathscr{0}}{0} 50$

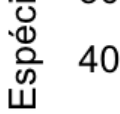

30

20

10

0

Semeadas (121) Estabelecidas (77) Colonizadoras (28) Floresta (22)

b

-Anemocoria $\backsim$ Autocoria $\square$ Zoocoria

100

90

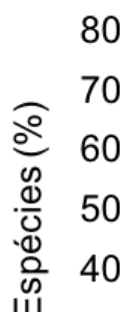

Ш 30

20

10

0

Semeadas (152) Estabelecidas (90) Colonizadoras (62) Floresta (68)

C

घPioneira n Não pioneira

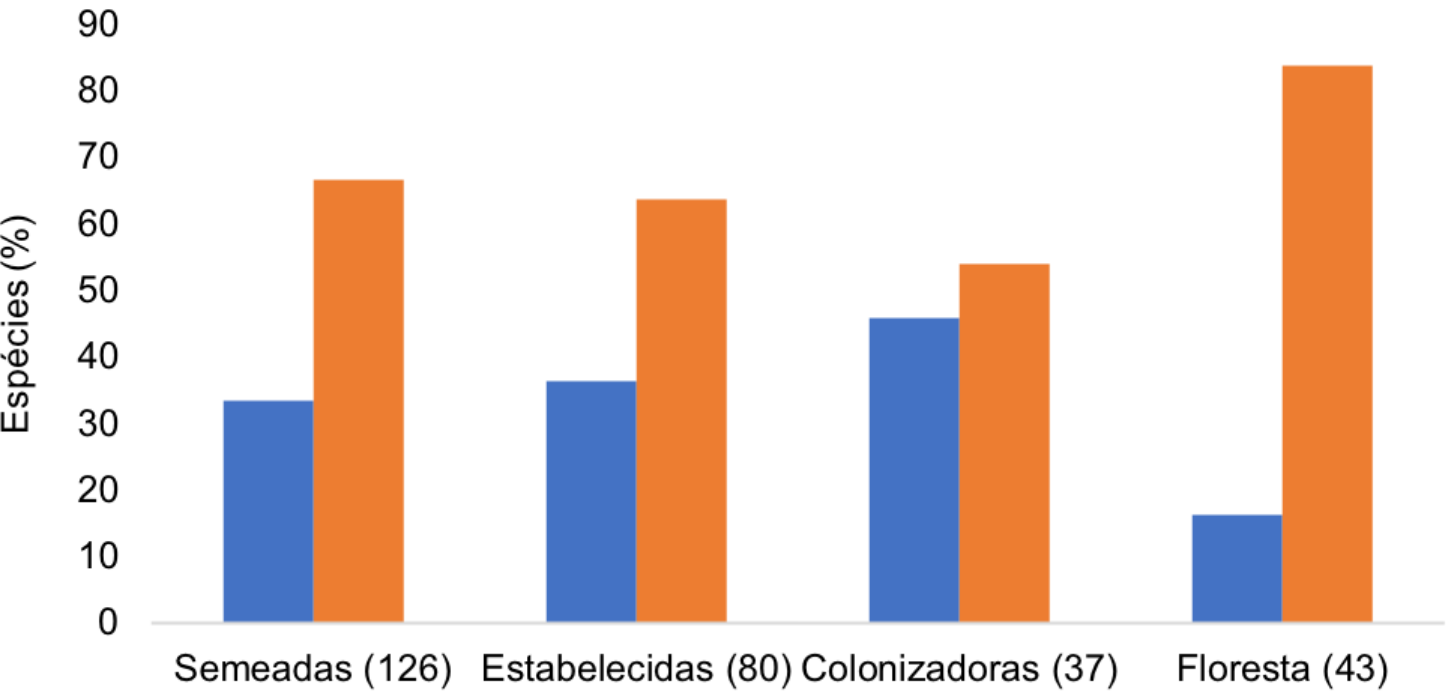

Figura 6 Classificação das espécies semeadas, colonizadoras e da floresta referência quanto a tolerância à dessecação (a), síndrome de dispersão (b) e classe sucessional (c). Espécies da floresta referência foram obtidas em Stefanello et al. (2010). 


\section{Efeito da paisagem na colonização de espécies}

Das 72 áreas estudadas, 39 apresentaram pelo menos uma espécie colonizadora. A porcentagem de cobertura de floresta dentro do buffer de $120 \mathrm{~m}$ variou entre 0 e $94 \%$. Das áreas estudadas, $55 \%$ tiveram menos de $20 \%$ de floresta dentro do buffer; $28 \%$ apresentaram entre 20 e $40 \%$ de floresta; $10 \%$ das áreas entre 40 e $60 \%$ de floresta; e apenas $7 \%$ tiveram mais de $60 \%$ de floresta. Apesar de $87 \%$ das espécies colonizadoras serem dispersas por animais, não foi encontrada relação entre a cobertura de floresta dentro do buffer e a densidade de espécies colonizadoras. No resultado da análise GLM, a equação com idade como única variável preditora do número de espécies colonizadoras foi a melhor (Tabela 1), tendo a idade da área um efeito significativo na densidade de colonizadoras. Todas as áreas com 10 anos (n =6) tiveram espécies colonizadoras, chegando em média uma densidade de cinco espécies por área (Figura 7).

Tabela 1 Resultado das análises dos modelos lineares generalizados (GLMs) do efeito das variáveis preditoras (idade, buffer 120, 200 e 500 m) no número de espécies colonizadoras. Em negrito GLM com variáveis significativas.

\begin{tabular}{lccl}
\hline Variável resposta/modelo & G.L. & Z value & $\operatorname{Pr}(>|\mathrm{z}|)$ \\
\hline Número de espécies colonizadoras & & & \\
Idade & $\mathbf{7 1}$ & $\mathbf{2 , 0 4}$ & $\mathbf{0 , 0 4 1}$ \\
Área de floresta $120 \mathrm{~m}$ & 71 & -0.163 & 0,870 \\
Área de floresta $200 \mathrm{~m}$ & 71 & 0.331 & 0.7403 \\
Área de floresta $500 \mathrm{~m}$ & 71 & 0.860 & 0.3899 \\
Idade : Área de floresta $120 \mathrm{~m}$ & 71 & -0.029 & 0.9766 \\
Idade : Área de floresta $200 \mathrm{~m}$ & 71 & -0.059 & 0.9531 \\
Idade : Área de floresta $500 \mathrm{~m}$ & 71 & -0.007 & 0.9943
\end{tabular}




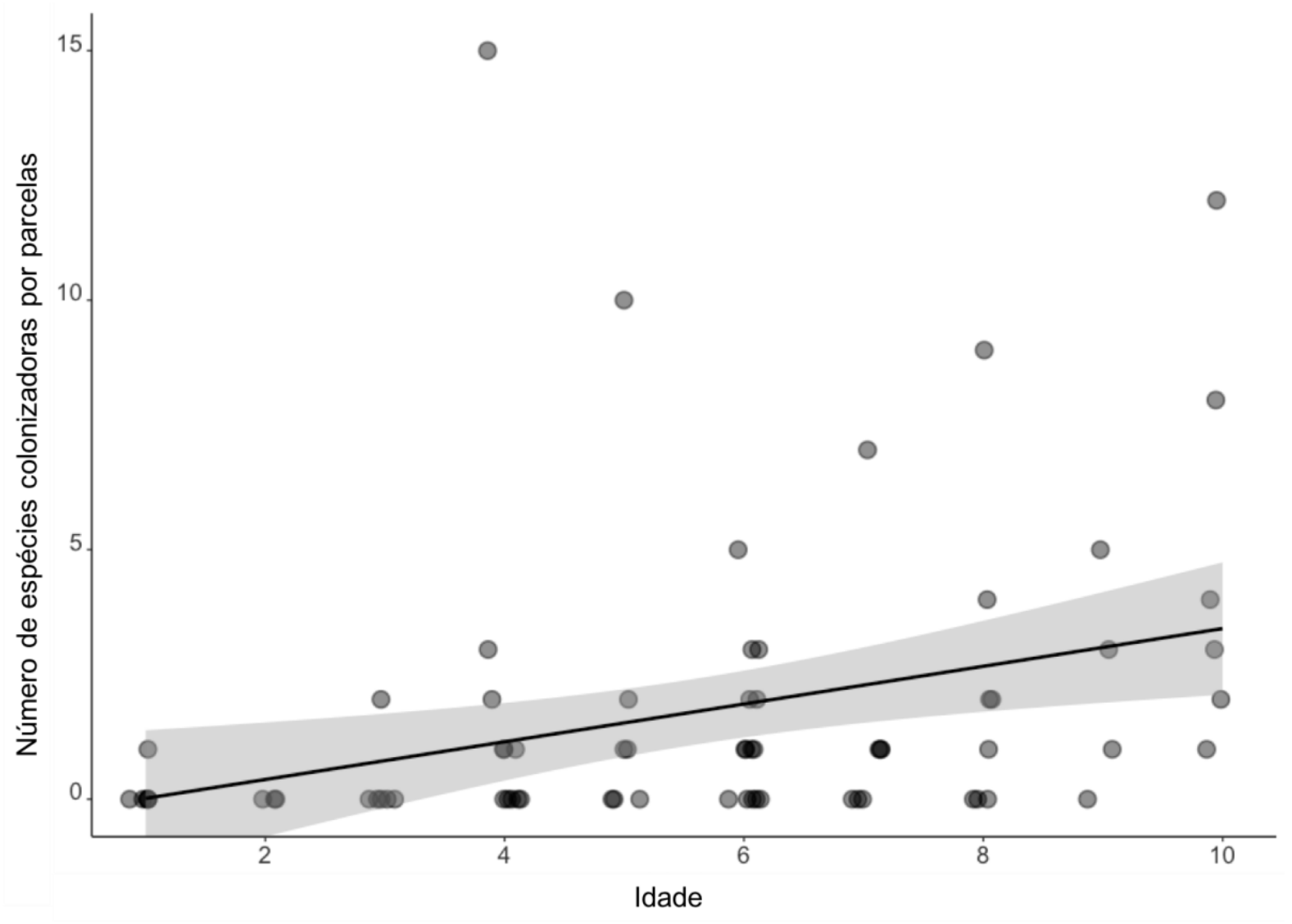

Figura 7 Relação entre a idade e o número de espécies colonizadoras por parcelas (amostragem em $500 \mathrm{~m}^{2}$ para indivíduos $\mathrm{H}>1,30 \mathrm{~m}$ e DAP $\geq 10 \mathrm{~cm} ; 100 \mathrm{~m}^{2}$ para indivíduos $\mathrm{H}>1,30 \mathrm{~m}$ e DAP < $10 \mathrm{~cm}$; e $25 \mathrm{~m}^{2}$ para indivíduos $0,3 \leq \mathrm{H} \leq 1,3 \mathrm{~m}$ ). A linha mostra a relação prevista e a área sombreada indicam intervalo de confiança de 95\%. Os pontos foram deslocados horizontalmente para evitar sobreposição das áreas.

\section{Discussão}

Em apenas 10 anos, as áreas restauradas por semeadura direta tiveram rápida dinâmica sucessional de composição de espécies, análoga às mudanças que ocorrem na estrutura e na composição da vegetação durante a primeira década de sucessão em florestas tropicais (Chazdon, 2008). Apesar de não ter resultados sobre a mudança na composição durante os primeiros meses após a semeadura direta, nesse período ervas, arbustos, cipós nativos e gramíneas exóticas de pastagens recobrem o solo (Campos-Filho et al., 2013). Após o primeiro ano, espécies pioneiras de crescimento rápido, especialmente $M$. fistulifera, se destacaram pela grande densidade de indivíduos. O dossel fechou aos quatro anos de idade (média de $77 \%$ de cobertura do solo, variando entre 39 e 92\%), e considerando as áreas com maior sucesso, a cobertura de dossel foi de $90 \%$ (Freitas, 2018). Tachigali vulgaris, E. timbouva e A. cf. 
peregrina são espécies heliófitas de rápido crescimento que tiveram grande sucesso de estabelecimento por semeadura direta e contribuíram para a rápida formação do dossel após os quatro anos de idade. Hymenaea coubaril, D. alata, M. urundeuva e A. fraxinifolium são espécies de crescimento mais lento que formaram um sub-dossel e o estrato de regenerantes. Estas espécies têm ciclo de vida longo e contribuem na formação de diferentes estratos. A presença de espécies de ciclo longo é de extrema importância para garantir a permanência das florestas em restauração enquanto espécies presentes na matriz florestal da paisagem lentamente as colonizam, já que espécies pioneiras de crescimento rápido que formam o dossel, como T. vulgaris e E. timbouva, morrem após 10 - 20 anos (Felfili et al., 1999; Wirth et al., 2009). Se não há espécies no sub-dossel, as áreas restauradas podem voltar a um estágio onde há dominância de capins exóticos (Rodrigues et al. 2009). Desta maneira, as espécies estabelecidas por semeadura direta contribuem na exclusão de gramíneas exóticas, para a melhora das condições microclimáticas e para o aumento na chuva de sementes (Holl, 2002), superando, assim, barreiras que impedem a regeneração natural. A maioria das espécies presentes exclusivamente na classe de regenerantes em áreas com mais de quatro anos foi de colonizadoras que chegaram por chuva de sementes, demonstrando o sucesso da semeadura direta em desencadear o processo de sucessão.

O relativo sucesso encontrado nas áreas restauradas, com estabelecimento de $62 \%$ das espécies semeadas, pode ser atribuído às técnicas utilizadas na implantação das áreas. As técnicas que contribuem para que os filtros associados à semeadura direta não seja tão severo após o plantio, como sugerem alguns estudos (Camargo et al., 2002; Knowles \& Parrotta, 1995), são a boa preparação do solo, utilização de grande quantidade de sementes, o controle de capins invasores agressivos e a utilização de leguminosas de ciclo de vida curto (Balandier et al., 2009a; Camargo et al., 2002; Doust et al., 2008; Knowles and Parrotta, 1995; Silva and Vieira, 2017). Todas estas técnicas foram empregadas nas áreas estudadas. A preparação do 
solo foi feita através de gradagem, buscando destorroar e nivelar ao máximo o terreno favorecendo o estabelecimento de espécies com sementes pequenas (Silva \& Vieira 2017). O controle de capins invasores com herbicida seletivo foi realizado durante o primeiro ano, contribuindo para acelerar o crescimento e aumentar a sobrevivência das espécies semeadas (Doust et al., 2008). Espécies leguminosas foram utilizadas, com o objetivo de atuarem como plantas facilitadoras nos primeiros anos, melhorando as condições químicas e físicas do solo e protegendo plântulas de árvores de condições climáticas extremas ( Balandier et al. 2009; Vieira et al., 2009). Por fim, para as áreas estudadas, foi feito um cálculo para determinar a quantidade de sementes de cada espécie a ser utilizada por hectare, levando-se em conta a porcentagem de germinação em campo e o número de plântulas que se deseja estabelecer (Guerin et al. 2015). Considerando que espécies de sementes pequenas apresentam porcentagem de germinação menor do que sementes grandes, estas são plantadas em maiores quantidades, havendo assim uma compensação da baixa germinação das sementes pequenas na quantidade utilizada.

No entanto, a semeadura direta está associada à filtros ecológicos que selecionaram as espécies amostradas neste estudo antes do plantio ser realizado. O primeiro filtro pré-plantio se dá diante da necessidade de armazenamento das sementes, que limita a utilização daquelas recalcitrantes, geralmente pertencentes a espécies zoocóricas. A campanha Y Ikatu Xingu fez nascer uma associação de coletores de sementes, a Rede de Sementes do Xingu, que se responsabilizou pela produção de sementes utilizadas na restauração das áreas estudadas. Para atender à grande demanda, foi necessária a estruturação de uma complexa cadeia produtiva que envolve, entre outros fatores, a coleta, o armazenamento, o controle de qualidade e a comercialização das sementes (Urzedo, 2014). Coletores de sementes após a colheita beneficiam os frutos para a extração de sementes que posteriormente passam por um processo de secagem para serem armazenadas (Urzedo, 2014), inviabilizando assim a inclusão entre as 
sementes plantadas de muitas espécies típicas de florestas de referência que têm sementes recalcitrantes. Além deste, um outro filtro que limita o uso de espécies zoocóricas é a época de plantio. A semeadura direta começam no início da estação chuvosa para que as plântulas aproveitem todo o período para crescer e conseguir sobreviver à estação seca seguinte (Vieira et al., 2008). Grande parte das espécies zoocóricas nas florestas da região estudada frutificam no início da estação chuvosa (Ivanauskas et al., 2004), coincidindo com a época de plantio. Devido à cadeia produtiva existente, é inviável o uso de sementes que ficam disponíveis somente na época do plantio. Embora estes filtros sejam atuantes, eles não excluem totalmente espécies recalcitrantes e zoocóricas. Nas áreas estudadas foram amostradas espécies semeadas com estas características, como por exemplo, Eugenia dysenterica e Calophyllum brasiliense (Campos-Filho \& Sartorelli, 2015; Mori et al., 2012).

A estruturação das áreas em restauração pelas espécies que passaram pelos filtros associados à semeadura direta criou um ambiente favorável ao estabelecimento de espécies colonizadoras do conjunto de espécies da comunidade vegetal regional, dirigindo as áreas restauradas no sentido da floresta de referência, considerando as características funcionais de tipo de semente e síndrome de dispersão. Porém, espécies colonizadoras e espécies da floresta de referência diferiram em relação à proporção das classes sucessionais. A presença de espécies colonizadoras pioneiras pode ser explicada pela alta capacidade de dispersão dessas espécies, que geralmente apresentam sementes pequenas e são produzidas em grande quantidade (Wirth et al., 2009), como é o caso de Cecropia pachystachya e Tapirira guianensis. Por outro lado, espécies não pioneira apresentam dispersão mais limitada por terem sementes grandes e produzidas em pequenas quantidades (Wirth et al., 2009), apesar de algumas terem sido amostradas nas áreas em restauração, como Agonandra brasiliensis e Brosimum gaudichaudii. É necessário monitorar por mais tempo o ingresso de espécies e grupos funcionais para planejar uma possível reintrodução de espécies que não têm permeabilidade na paisagem. 
As espécies colonizadoras foram capazes de chegar nas áreas restauradas mesmo em uma paisagem bastante desmatada. No entanto, não foi encontrada relação entre a área de floresta no buffer e a chegada de espécies colonizadoras, apesar da grande amplitude de cobertura de floresta entre as paisagens avaliadas. Este resultado pode ser atribuído a fatores como a distância do fragmento de floresta mais próximo e o histórico de uso do solo, o tempo de uso e sua intensidade. Em um estudo no sudoeste da Amazônia, Rocha et al (2016) também não encontraram influência da área de floresta em um raio de 120 m na regeneração natural em pastagens abandonadas, atribuindo tal resultado à dispersão de sementes limitada para muitas espécies na região tropical, que ocorre somente até alguns metros de distância da borda da floresta (Howe \& Pantaleon 2010) e outras com ampla dispersão, dispersas principalmente por morcegos que apresentam uma capacidade dispersora de média-longa distância $(0,1-2,3 \mathrm{~km}$; Bernard \& Fanton 2003). Por fim, as áreas estudadas têm até 10 anos de idade, tempo que pode ser relativamente curto para se observar efeito da cobertura de floresta na paisagem na chegada de espécies, embora espera-se que com o tempo tal influência possa aumentar (Holl et al., 2017).

\section{Considerações finais}

A semeadura direta vem sendo utilizada com sucesso na restauração de áreas degradadas na região da bacia do Alto Xingu. As espécies semeadas estabelecidas criaram uma floresta estratificada e contribuíram para desencadear o processo de sucessão secundária mesmo após passarem por filtros ecológicos associados à semeadura direta. As técnicas utilizadas na implantação das áreas podem ter contribuído para que estes filtros não fossem tão severos. No entanto, ainda são necessárias mais investigações sobre germinação de sementes de espécies nativas e incorporação de outras técnicas para aumentar o espectro de espécies estabelecidas como, por exemplo, peletização de sementes. Contratos e arranjos para a execução da restauração devem considerar diferentes requerimentos das espécies nativas a fim 
de contemplar maior diversidade. Além disso, é importante verificar quais são e se as espécies semeadas sem sucesso ainda estão sendo semeadas, além de investigar o que pode ser feito para reduzir o desperdício de sementes. A chegada de espécies colonizadoras faz com que as áreas restauradas se tornem mais semelhantes às florestas maduras da região. A continuidade do monitoramento destas áreas é necessária para verificar se espécies não-pioneiras continuarão chegando, pois caso isto não aconteça, medidas de manejo podem ser necessárias para aumentar a diversidade de espécies. 


\section{Referências Bibliográficas}

Aguirre, A.G., Lima, J.T., Teixeira, J., Gandolfi, S., 2015. Potencial da semeadura direta na restauração florestal de pastagem abandonada no município de Piracaia, SP, Brasil. Hoehnea 42, 629-640. https://doi.org/10.1590/2236-8906-04/RAD/2015

Aliança, pela R. da A., 2017. Aliança pela Restauração na Amazônia [WWW Document]. URL http://aliancaamazonia.org.br (accessed 1.20.18).

Balandier, P., Frochot, H., Sourisseau, A., 2009a. Improvement of direct tree seeding with cover crops in afforestation: Microclimate and resource availability induced by vegetation composition. For. Ecol. Manage. 257, 1716-1724. https://doi.org/10.1016/j.foreco.2009.01.032

Barton, S., McElhinny, C., 2012. Shrubby today but not tomorrow ? Structure, composition and regeneration dynamics of direct seeded revegetation. Ecol. Manag. Restor. 13. https://doi.org/10.1111/emr.12007

Bonilla-Moheno, M., Holl, K.D., 2010. Direct Seeding to Restore Tropical Mature-Forest Species in Areas of Slash-and-Burn Agriculture. Restor. Ecol. 18, 438-445. https://doi.org/10.1111/j.1526-100X.2009.00580.x

Brasil, 2012. Código Florestal Brasileiro. Diário Oficial da União de 28 de maio de 2012.

Camargo, J.L.C., Ferraz, I.D.K., Imakawa, A.M., 2002. Rehabilitation of degraded areas of Central Amazonia using direct sowing of forest tree seeds. Restor. Ecol. 10, 636-644. https://doi.org/10.1046/j.1526-100X.2002.01044.x

Campos-Filho, E.M., Da Costa, J.N.M.N., De Sousa, O.L., Junqueira, R.G.P., 2013. Mechanized Direct-Seeding of Native Forests in Xingu, Central Brazil. J. Sustain. For. 32, 702-727. https://doi.org/10.1080/10549811.2013.817341

Campos-Filho, E.M., Sartorelli, P.A.R., 2015. Guia de identificação de espécies-chave para a restauração florestal na região de Alto Pires Mato Grosso. The Nature Conservancy, São Paulo.

Castro, D.J.L. de, 2012. Características funcionais de espécies arbóreas de diferentes estádios sucessionais na várzea da amazônia central. Instituto Nacional de Pesquisas da Amazônia.

Chazdon, R., 2012. Tropical forest regeneration. Bol. Do Mus. Para. Emilio Goeldi. Ciências Nat. 7, 195-218.

Chazdon, R.L., 2008. Chance and Determinism in Tropical Forest Succession, in: Carson, W.P., Schnitzer, S.A. (Eds.), Tropical Forest Community Ecology. Wiley-Blackwell, p. 517.

Conserva, A.D.S., Santana, D.G. de, Piedade, M.T.F., 2013. Seed Features of Important Timber Species From the Floodplain Várzea Forest: Implications for Ex Situ Conservation Programs in the Amazon. Uakari 9, 12.

Corbin, J.D., Holl, K.D., 2012. Applied nucleation as a forest restoration strategy. For. Ecol. Manage. 265, 37-46. https://doi.org/10.1016/j.foreco.2011.10.013

Corlett, R.T., Primack, R.B., 2008. Tropical Rainforest Conservation: A Global Perspective, in: Carson, W.P., Schnitzer, S.A. (Eds.), Tropical Forest Community Ecology. WileyBlackwell, p. 517. 
Costa, C.J., 2009. Armazenamento e conservação de sementes do Cerrado. Planaltina - DF.

Cruz, E.D., de Sena, A.L., Lopes, B.C., 2016. Germinação de sementes de espécies amazônicas: mogno (Swietenia macrophylla King). Belém - PA.

Delgado, L.F., Barbedo, C.J., 2007. Tolerância à dessecação de sementes de espécies de Eugenia. Pesqui. Agropecu. Bras. 42, 265-272. https://doi.org/10.1590/S0100204X2007000200016

Doust, S.J., Erskine, P.D., Lamb, D., 2008. Restoring rainforest species by direct seeding: Tree seedling establishment and growth performance on degraded land in the wet tropics of Australia. For. Ecol. Manage. 256, 1178-1188. https://doi.org/10.1016/j.foreco.2008.06.019

Doust, S.J., Erskine, P.D., Lamb, D., 2006. Direct seeding to restore rainforest species: Microsite effects on the early establishment and growth of rainforest tree seedlings on degraded land in the wet tropics of Australia. For. Ecol. Manage. 234, 333-343. https://doi.org/10.1016/j.foreco.2006.07.014

Engel, V.L.., Parrotta, J.A.., 2001. An evaluation of direct seeding for reforestation of degraded lands in central São Paulo state, Brazil. For. Ecol. Manage. 152, 169-181. https://doi.org/10.1016/S0378-1127(00)00600-9

FAO, 2015. Global forest resources assessment 2015: how are the world's forests changing? Roma, Italia.

Fearnside, P.M., 2005. Deforestation in Brazilian Amazonia: history, rates, and consequences. Conserv. Biol. 19, 680-688.

Felfili, J.M., Hilgbert, L.F., Franco, A.C., Sousa-silva, J.C., Resende, A. V, Nogueira, M.V., 1999. Comportamento de plântulas de Sclerolobium paniculatum Vog. var. rubiginosum (Tul.) Benth. sob diferentes níveis de sombreamento, em viveiro. Rev. Bras. Botânica 2, 297-301. https://doi.org/10.1590/S0100-84041999000500011

Ferreira, M.C., Vieira, D.L.M., 2017. Topsoil for restoration: Resprouting of root fragments and germination of pioneers trigger tropical dry forest regeneration. Ecol. Eng. 103, 112. https://doi.org/10.1016/j.ecoleng.2017.03.006

Ferreira, R.A., Santos, P.L., De Aragão, A.G., Santos, T.I.S., Neto, E.M.D.S., Da Silva Rezende, E.A.M., 2009. Semeadura direta com esp??cies florestais na implantação de mata ciliar no Baixo São Francisco em Sergipe. Sci. For. Sci. 37, 37-46.

Florentine, S.K., Graz, F.P., Ambrose, G., O’brien, L., 2013. The Current Status Of Different Age, Direct-Seeded Revegetation Sites In An Agricultural Landscape In The Burrumbeet Region, Victoria, Australia. L. Degrad. Dev. 24, 81-89. https://doi.org/10.1002/ldr.1110

Freitas, M.G., 2018. Estrutura e riqueza de florestas restauradas por semeadura direta ao longo de 10 anos. Universidade de Brasília.

Garwood, N.C., Lighton, J.R.B., 1990. Physiological ecology of seed respiration in some tropical species. New Phytol. 115, 549-558. https://doi.org/10.2307/2556659

Gouveia, D., Soares, M., Silva, W., Mazzei, L., Ruschel, A., 2011. AVALIAÇÃO DO CRESCIMENTO DE ESPÉCIES FLORESTAIS POR GRUPO ECOLÓGICO EM ÁREAS EXPLORADAS NA FLONA DO Tapajós. III Encontro Amaz. Agrárias 1-5.

Greenpeace, 2016. Damning the Amazon: The Risky Business of Hydropower in the Amazon. 
Guarino, E. de S.G., Scariot, A., 2014. Direct seeding of dry forest tree species in abandoned pastures: Effects of grass canopy and seed burial on germination. Ecol. Res. 29, 473482. https://doi.org/10.1007/s11284-014-1143-4

Guerin, N., Isernhagen, I., Vieira, D.L.M., Campos-Filho, E.M., Campos, R.J.B., 2015. Avanços e próximos desafios da semeadura direta para restauração ecológica, in: Martins, S.V. (Ed.), Restauração Ecológica de Ecossistemas Degradados. Ed. UFV, Viçosa, MG, p. 376.

Hansen, M.C., Stehman, S.V., Potapov, P.V., Loveland, T.R., Townshend, J.R.G., DeFries, R.S., Pittman, K.W., Arunarwati, B., Stolle, F., Steininger, M.K., Carroll, M., DiMiceli, C., 2008. Humid tropical forest clearing from 2000 to 2005 quantified by using multitemporal and multiresolution remotely sensed data. Proc. Natl. Acad. Sci. U.S.A 9439-9444.

Holl, B.K.D., 2017. Restoring tropical forests from the bottom up. Science (80-. ). 355, 445456.

Holl, K.D., 2002. Tropical moist forest, in: Handbook of Restoration. pp. 539-558.

Holl, K.D., Reid, J.L., Chaves-Fallas, J.M., Oviedo-Brenes, F., Zahawi, R.A., 2017. Local tropical forest restoration strategies affect tree recruitment more strongly than does landscape forest cover. J. Appl. Ecol. 54, 1091-1099. https://doi.org/10.1111/13652664.12814

Hooper, E., Condit, R., Legendre, P., 2002. Responses of 20 Native Tree Species to Reforestation Strategies for Abandoned Farmland in Panama Published 12, 1626-1641.

ISA, 2017. Boletim Rede de Sementes do Xingu 10 anos.

Ivanauskas, N.M., Monteiro, R., Rodrigues, R.R., 2008. Classificação fitogeográfica das florestas do Alto Rio Xingu. Acta Amaz. 38, 387-402. https://doi.org/10.1590/S004459672008000300003

Ivanauskas, N.M., Monteiro, R., Rodrigues, R.R., 2004. Composição florística de trechos florestais na borda sul-amazônica. Acta Amaz. 34, 399-413.

https://doi.org/10.1590/S0044-59672004000300006

Ivanauskas, N.M., Monteiro, R., Rodrigues, R.R., 2003. Alterations following a fire in a forest community of Alto Rio Xingu. For. Ecol. Manage. 184, 239-250. https://doi.org/10.1016/S0378-1127(03)00156-7

Jakovac, C.C., Peña-Claros, M., Kuyper, T.W., Bongers, F., 2015. Loss of secondary-forest resilience by land-use intensification in the Amazon. J. Ecol. 67-77. https://doi.org/10.1111/1365-2745.12298

Knowles, O.H., Parrotta, J.A., 1995. Amazonian forest restoration: an innovative system for native species selection based on phenological data and field performance indices 74 , 230-243.

Kunz, S.H., Ivanauskas, N.M., Martins, S.V., Silva, E., Stefanello, D., 2009. Análise da similaridade florística entre florestas do Alto Rio Xingu, da Bacia Amazônica e do Planalto Central. Rev. Bras. Botânica 32, 725-736. https://doi.org/10.1590/S010084042009000400011

Kunz, S.H., Ivanauskas, N.M., Martins, S.V., Silva, E., Stefanello, D., 2008. Aspectos florísticos e fitossociológicos de um trecho de Floresta Estacional Perenifólia na Fazenda Trairão, Bacia do rio das Pacas, Querência-MT. Acta Amaz. 38, 245-254. 
https://doi.org/10.1590/S0044-59672008000200007

Lima, V.V.F. de, Vieira, D.L.M., Sevilha, A.C., Salomão, A.N., 2008. Germinação de espécies arbóreas de floresta estacional decidual do vale do rio Paranã em Goiás após três tipos de armazenamento por até 15 meses. Biota Neotrop. 8, 89-97. https://doi.org/10.1590/S1676-06032008000300008

MapBiomas, P., n.d. Coleção 1 da Série Anual de Mapas de Cobertura e Uso de Solo do Brasil [WWW Document]. URL http://mapbiomas.org/pages/database/mapbiomas_collection (accessed 1.1.17).

Marimon, B.S., Felfili, J.M., Haridasan, M., 2001. Studies in Monodominant Forests in Eastern Mato Grosso, Brazil: I. a Forest of Brosimum Rubescens Taub. Edinburgh J. Bot. 58, 483-497. https://doi.org/10.1017/S096042860100049X

Mayrinck, R.C., Vaz, T.A.A., Davide, A.C., 2016. Classificação fisiológica de sementes florestais quanto à tolerância à dessecação e ao comportamento no armazenamento. Cerne 22, 85-92. https://doi.org/10.1590/01047760201622012064

Meli, P., Isernhagen, I., Brancalion, P.H.S., Isernhagen, E.C.C., Behling, M., Rodrigues, R.R., 2017. Optimizing seeding density of fast-growing native trees for restoring the Brazilian Atlantic Forest. Restor. Ecol. 1-8. https://doi.org/10.1111/rec.12567

Mesquita, R.C.G., Ickes, K., Ganade, G., Williamson, G.B., 2001. Alternative succesional pathways in the amazon basin. J. Ecol. 89, 528-537.

Mori, E.S., Piña-Rodrigues, F.C.M., Freitas, N.P. de, 2012. Sementes florestais: Guia para germinação de 100 espécies nativas, 1st ed. Instituto Refloresta, São Paulo.

Moura, R., 2018. Ainda é pouco: "Maior projeto de reflorestamento da história" recupera menos de 5\% do desmatamento anual na Amazônia. BBC Bras.

http://www.bbc.com/portuguese/internacional-42485742

Neto, E.L.V., 2012. Agrupamento ecológico e funcional de espécies florestais na Amazônia sul ocidental. Universidadefederal do Amazonas.

Palma, A.C., Laurance, S.G.W., 2015. A review of the use of direct seeding and seedling plantings in restoration: what do we know and where should we go? Appl. Veg. Sci. 18, n/a-n/a. https://doi.org/10.1111/avsc.12173

Parrotta, J. a, Knowles, O.H., 1999. Restoring tropical forests on bauxite mined lands: lessons from the Brazilian Amazon. Ecol. Eng. (Submitted, 23 pages.

Peres, C.A., Gardner, T.A., Barlow, J., Zuanon, J., Michalski, F., Lees, A.C., Vieira, I.C.G., Moreira, F.M.S., Feeley, K.J., 2010. Biodiversity conservation in human-modified Amazonian forest landscapes. Biol. Conserv. 143, 2314-2327. https://doi.org/10.1016/j.biocon.2010.01.021

Quinn, G.P., Keough, M.J., 2002. Experimental Design and Data analysis for Biologists. Cambridge University Press.

Rocha, G.P.E., Vieira, D.L.M., Simon, M.F., 2016. Fast natural regeneration in abandoned pastures in southern Amazonia. For. Ecol. Manage.

Rodrigues, R.R., Lima, R. a F., Gandolfi, S., Nave, A.G., 2009. On the restoration of high diversity forests: 30 years of experience in the Brazilian Atlantic Forest. Biol. Conserv. 142, 1242-1251. https://doi.org/10.1016/j.biocon.2008.12.008

Sampaio, A.B., Holl, K.D., Scariot, A., 2007. Does Restoration Enhance Regeneration of 
Seasonal Deciduous Forests in Pastures in Central Brazil ? 15, 462-471.

Sansevero, J.B.B., Prieto, P.V., de Moraes, L.F.D., Rodrigues, P.J.F.P., 2011. Natural regeneration in plantations of native trees in lowland Brazilian Atlantic forest: Community structure, diversity, and dispersal syndromes. Restor. Ecol. 19, 379-389. https://doi.org/10.1111/j.1526-100X.2009.00556.x

Santos, L.A.G. dos, 2013. Estrutura, riqueza, diversidade e grupos funcionais da comunidade arbórea em um remanescente de floresta estacional semidecidual no Espinhaço meriodional. Universidade Federal dos Vales do Jequitinhonha e Mucuri.

Sena, L.H. d. M., Matos, V.P., Medeiros, J.E. de, Santos, H.H.D., 2016. STORAGE OF PITOMBEIRA SEEDS [Talisia esculenta (A. St. Hil) Radlk - SAPINDACEAE] IN DIFFERENT ENVIRONMENTS AND PACKAGINGS. Rev. Árvore 40, 435-445.

SER, 2004. Society for Ecological Restoration [WWW Document].

Silva, R.R.P., Oliveira, D.R., da Rocha, G.P.E., Vieira, D.L.M., 2015. Direct seeding of Brazilian savanna trees: effects of plant cover and fertilization on seedling establishment and growth. Restor. Ecol. 23, 393-401. https://doi.org/10.1111/rec.12213

Silva, R.R.P., Vieira, D.L.M., 2017. Direct seeding of 16 Brazilian savanna trees: responses to seed burial, mulching and an invasive grass. Appl. Veg. Sci. 20, 410-421. https://doi.org/10.1111/avsc.12305

Sovu, Savadogo, P., Tigabu, M., Odén, P.C., 2010. Restoration of Former Grazing Lands in the Highlands of Laos Using Direct Seeding of Four Native Tree Species. Mt. Res. Dev. 30, 232-243. https://doi.org/10.1659/MRD-JOURNAL-D-10-00031.1

Stefanello, D., Fernandes-Bulhão, C., Martins, S.V., 2009. Síndromes de dispersão de sementes em três trechos de vegetação ciliar (nascente, meio e foz) ao longo do rio Pindaíba, MT. Rev. Árvore 33, 1051-1061. https://doi.org/10.1590/S010067622009000600008

Swaine, M.D., Whitmore, T.C., 1988. On the definition of ecological species groups in tropical rain forests. Vegetatio 75, 81-86. https://doi.org/10.1007/BF00044629

Urzedo, D.I. de, 2014. Trilhando recomeços : A socioeconomia da produção de sementes florestais do Alto Xingu na Amazônia brasileira 130.

Velasquez, C., Queiroz, H., Bernasconi, P., 2010. Fique por dentro: a Bacia do Rio Xingu em Mato Grosso.

Viani, R.A.G., Holl, K.D., Padovezi, A., Strassburg, B.B.N., Farah, F.T., Garcia, L.C., Chaves, R.B., Rodrigues, R.R., Brancalion, P.H.S., 2017. Protocol for Monitoring Tropical Forest Restoration. Trop. Conserv. Sci. 10, 194008291769726. https://doi.org/10.1177/1940082917697265

Vieira, D.L., Scariot, A., 2006. Principles of natural regeneration of Tropical Dry Forests for regeneration. Restor. Ecol. 14, 11-20. https://doi.org/10.1111/j.1526100X.2006.00100.X

Vieira, D.L.M., Holl, K.D., Peneireiro, F.M., 2009. Agro-successional restoration as a strategy to facilitate tropical forest recovery. Restor. Ecol. 17, 451-459. https://doi.org/10.1111/j.1526-100X.2009.00570.x

Vieira, D.L.M., Lima, V.V.F. de, Sevilha, A.C., Scariot, A., 2008. Forest Ecology and Management Consequences of dry-season seed dispersal on seedling establishment of dry forest trees : Should we store seeds until the rains ? For. Ecol. Manage. 256, 471- 
481. https://doi.org/10.1016/j.foreco.2008.04.052

Villas-Boas, A., 2012. De Olho na Bacia do Xingu. Série Cart. Bras. Socioambiental 5, 63. https://doi.org/10.1017/CBO9781107415324.004

Wirth, C., Messier, C., Bergeron, Y., Frank, D., Frankhanel, A., 2009. Old-Growth Forest Definitions: a Pragmatic View, in: Wirth, C., Gleixner, G., Heimann, M. (Eds.), OldGrowth Forests. Ecological Studies (Analysis and Synthesis). Springer Berlin Heidelberg, pp. 129-145. https://doi.org/10.1007/978

Zar, J.H., 2010. Biostatistical Analysis, 5th ed. Pearson Education. 


\section{Material Suplementar}

Tabela S1 Relação de espécies utilizadas em plantios de semeadura direta para restauração de áreas degradadas na bacia do alto Xingu, MT. Elaborada a partir da lista utilizada em 17 plantios.

\begin{tabular}{|c|c|}
\hline Família & Espécies \\
\hline \multirow[t]{7}{*}{ Anacardiaceae } & Anacardium humile A. St.-Hil. \\
\hline & Anacardium nanum A. St.-Hil. \\
\hline & Anacardium occidentale L. \\
\hline & Astronium fraxinifolium Schott \\
\hline & Myracrodruon urundeuva Allemão \\
\hline & Spondias mombin L. \\
\hline & Thyrsodium spruceanum Benth. \\
\hline \multirow[t]{6}{*}{ Annonaceae } & Annona cacans Warm. \\
\hline & Annona crassiflora Mart. \\
\hline & Annona muricata $\mathrm{L}$. \\
\hline & Annona sp. \\
\hline & Xylopia amazonica R. E. Fr. \\
\hline & Xylopia aromatica (Lam.) Mart. \\
\hline \multirow{5}{*}{ Apocynaceae } & Aspidosperma discolor A. DC. \\
\hline & Aspidosperma sp. \\
\hline & Aspidosperma subincanum Mart. \\
\hline & Himatanthus articulatus (Vahl) Woodson \\
\hline & Himatanthus obovatus (Müll. Arg.) Woodson \\
\hline Araliaceae & Schefflera morototoni (Aubl.) Maguire et al. \\
\hline \multirow[t]{9}{*}{ Bignoniaceae } & Cybistax antisyphilitica (Mart.) Mart. \\
\hline & Handroanthus impetiginosus (Mart. ex DC.) Mattos \\
\hline & Handroanthus ochraceus (Cham.) Mattos \\
\hline & Handroanthus serratifolius (Vahl) S.Grose \\
\hline & Jacaranda brasiliana (Lam.) Pers. \\
\hline & Jacaranda copaia (Aubl.) D.Don \\
\hline & Jacaranda cuspidifolia Mart. \\
\hline & Tabebuia aurea (Silva Manso) Benth. \& Hook.f. ex S.Moore \\
\hline & Tabebuia roseoalba (Ridl.) Sandwith \\
\hline \multirow[t]{2}{*}{ Bixaceae } & Bixa orellana L. \\
\hline & Cochlospermum orinocense (Kunth) Steud. \\
\hline \multirow[t]{2}{*}{ Burseraceae } & Protium heptaphyllum (Aubl.) Marchand \\
\hline & Trattinickia rhoifolia Willd. \\
\hline Calophyllaceae & Calophyllum brasiliense Cambess. \\
\hline Cannabaceae & Trema micrantha (L.) Blume \\
\hline Caricaceae & Carica papaya L. \\
\hline
\end{tabular}




\begin{tabular}{|c|c|}
\hline Caryocaraceae & Caryocar brasiliense Cambess. \\
\hline Chrysobalanaceae & Couepia grandiflora (Mart. \& Zucc.) Benth. \\
\hline \multirow[t]{4}{*}{ Combretaceae } & Buchenavia macrophylla Eichler \\
\hline & Buchenavia tetraphylla (Aubl.) R.A.Howard \\
\hline & Buchenavia tomentosa Eichler \\
\hline & Terminalia argentea Mart. \\
\hline Dilleniaceae & Curatella americana $\mathrm{L}$. \\
\hline Ebenaceae & Diospyros hispida A. DC. \\
\hline \multirow[t]{5}{*}{ Euphorbiaceae } & Aparisthmium cordatum (A. Juss.) Baill. \\
\hline & Croton urucurana Baill. \\
\hline & Mabea angustifolia Spruce ex Benth. \\
\hline & Mabea fistulifera Mart. \\
\hline & Mabea pohliana (Benth.) Müll. Arg. \\
\hline \multirow[t]{30}{*}{ Fabaceae } & Adenanthera pavonina L. \\
\hline & Anadenanthera cf. colubrina (L.) Speg. \\
\hline & Anadenanthera cf. peregrina (Benth.) Altschul \\
\hline & Andira cujabensis Benth. \\
\hline & Andira vermifuga (Mart.) Benth. \\
\hline & Apuleia leiocarpa (Vogel) J.F.Macbr. \\
\hline & Bauhinia rufa (Bong.) Steud. \\
\hline & Bauhinia sp. 1 \\
\hline & Bauhinia sp.2 \\
\hline & Bowdichia virgilioides Kunth \\
\hline & Chloroleucon mangense (Jacq.) Britton \& Rose \\
\hline & Clitoria fairchildiana R.A.Howard \\
\hline & Copaifera langsdorffii Desf. \\
\hline & Copaifera marginata Benth. \\
\hline & Dialium guianense (Aubl.) Sandwith \\
\hline & Dimorphandra mollis Benth. \\
\hline & Dipteryx alata Vogel \\
\hline & Dipteryx odorata (Aubl.) Willd. \\
\hline & Enterolobium maximum Ducke \\
\hline & Enterolobium schomburgkii (Benth.) Benth. \\
\hline & Enterolobium timbouva Mart. \\
\hline & Erythrina cristagalli $\mathrm{L}$. \\
\hline & Hymenaea courbaril L. \\
\hline & Hymenaea martiana Hayne \\
\hline & Hymenaea stigonocarpa Mart. ex Hayne \\
\hline & Machaerium acutifolium Vogel \\
\hline & Mimosa caesalpiniifolia Benth. \\
\hline & Ormosia excelsa Benth. \\
\hline & Ormosia paraensis Ducke \\
\hline & Parkia pendula (Willd.) Benth. ex Walp. \\
\hline
\end{tabular}


Peltogyne confertiflora (Mart. ex Hayne) Benth.

Plathymenia reticulata Benth.

Platypodium elegans Vogel

Pterodon pubescens (Benth.) Benth.

Pterogyne nitens Tul.

Samanea tubulosa (Benth.) Barneby \& J.W.Grimes

Schizolobium parahyba var. amazonicum (Huber ex Ducke)

Barneby

Senegalia mattogrossensis (Malme) Seigler \& Ebinger

Senegalia polyphylla (DC.) Britton \& Rose

Senna alata (L.) Roxb.

Senna silvestris (Vell.) H.S. Irwin \& Barneby

Stryphnodendron adstringens (Mart.) Coville

Tachigali bracteosa (Harms) Zarucchi \& Pipoly

Tachigali chrysaloides van der Werff

Tachigali vulgaris L. F. Gomes Silva \& H. C. Lima

Tamarindus indica $\mathrm{L}$.

Vatairea macrocarpa (Benth.) Ducke

Humiriaceae Humiria balsamifera (Aubl.) A. St.-Hil.

Hypericaceae Vismia japurensis Reichardt

Icacinaceae Emmotum nitens (Benth.) Miers

Lamiaceae Tectona grandis L. f.

Vitex megapotamica (Spreng.) Moldenke

Loganiaceae Strychnos pseudoquina A. St.-Hil.

Lythraceae Lafoensia pacari A. St.-Hil.

Physocalymma scaberrimum Pohl

Malpighiaceae Byrsonima arthropoda A. Juss.

Byrsonima crisps A. Juss.

Byrsonima coccolobifolia Kunth

Byrsonima cydoniifolia A. Juss.

Byrsonima intermedia A. Juss.

Byrsonima pachyphylla A. Juss.

Byrsonima verbascifolia (L.) DC.

Malvaceae Apeiba tibourbou Aubl.

Ceiba speciosa (A. St.-Hil.) Ravenna

Eriotheca gracilipes (K. Schum.) A. Robyns

Guazuma ulmifolia Lam.

Luehea divaricata Mart. \& Zucc.

Sterculia striata A. St.-Hil. \& Naudin

Melastomataceae Bellucia grossularioides (L.) Triana

Mouriri acutiflora Naudin

Mouriri apiranga Spruce ex Triana

Mouriri pusa Gardner 


\begin{tabular}{|c|c|}
\hline Meliaceae & Swietenia macrophylla King \\
\hline Menispermaceae & Abuta grandifolia (Mart.) Sandwith \\
\hline \multirow[t]{2}{*}{ Moraceae } & Brosimum gaudichaudii Trécul \\
\hline & Maclura tinctoria (L.) D.Don ex Steud. \\
\hline Muntingiaceae & Muntingia calabura $\mathrm{L}$. \\
\hline Myristicaceae & Virola sebifera Aubl. \\
\hline \multirow[t]{6}{*}{ Myrtaceae } & Eugenia dysenterica (Mart.) DC. \\
\hline & Eugenia klotzschiana O. Berg \\
\hline & Eugenia uniflora L. \\
\hline & Myrcia amazonica DC. \\
\hline & Psidium guajava $\mathrm{L}$. \\
\hline & Syzygium cumini (L.) Skeels \\
\hline \multirow{2}{*}{ Peraceae } & Chaetocarpus echinocarpus (Baill.) Ducke \\
\hline & Pera coccinea (Benth.) Müll. Arg. \\
\hline Picrodendraceae & Piranhea trifoliata Baill. \\
\hline \multirow[t]{4}{*}{ Rubiaceae } & Alibertia edulis (Rich.) A.Rich. \\
\hline & Cordiera elliptica (Cham.) Kuntze \\
\hline & Cordiera macrophylla (K. Schum.) Kuntze \\
\hline & Genipa americana $\mathrm{L}$. \\
\hline Rutaceae & Zanthoxylum rhoifolium Lam. \\
\hline \multirow[t]{2}{*}{ Sapindaceae } & Magonia pubescens A. St.-Hil. \\
\hline & Talisia esculenta (Cambess.) Radlk. \\
\hline Sapotaceae & Pouteria macrophylla (Lam.) Eyma \\
\hline Siparunaceae & Siparuna guianensis Aubl. \\
\hline \multirow[t]{2}{*}{ Simaroubaceae } & Simarouba amara Aubl. \\
\hline & Simarouba versicolor A. St.-Hil. \\
\hline \multirow[t]{2}{*}{ Solanaceae } & Solanum cinnamomeum Sendtn. \\
\hline & Solanum lycocarpum A. St.-Hil. \\
\hline Urticaceae & Cecropia pachystachya Trécul \\
\hline \multirow[t]{3}{*}{ Vochysiaceae } & Qualea multiflora Mart. \\
\hline & Salvertia convallariodora A. St.-Hil. \\
\hline & Vochysia ferruginea Mart. \\
\hline
\end{tabular}


Tabela S2 Espécies amostradas em áreas restauradas por semeadura direta na bacia do Alto Xingu, MT, indicando frequência de parcelas em que cada espécie ocorreu.

\begin{tabular}{|c|c|c|c|c|c|c|c|c|c|c|c|}
\hline \multirow{2}{*}{ Família } & \multirow{2}{*}{ Espécies } & \multicolumn{10}{|c|}{ Idade (número total de parcelas) } \\
\hline & & $\begin{array}{c}1 \\
(n=6)\end{array}$ & $\begin{array}{c}2 \\
(n=3)\end{array}$ & $\begin{array}{c}3 \\
(n=6)\end{array}$ & $\begin{array}{c}4 \\
(n=11)\end{array}$ & $\begin{array}{c}5 \\
(n=7)\end{array}$ & $\begin{array}{c}6 \\
(n=14)\end{array}$ & $\begin{array}{c}7 \\
(n=7)\end{array}$ & $\begin{array}{c}8 \\
(n=8)\end{array}$ & $\begin{array}{c}9 \\
(n=4)\end{array}$ & $\begin{array}{c}10 \\
(\mathrm{n}=6)\end{array}$ \\
\hline \multirow[t]{6}{*}{ Anacardiaceae } & Anacardium nanum A.St.-Hil. & & & & & 2 & & 1 & & 1 & 1 \\
\hline & Astronium fraxinifolium Schott & 2 & 2 & 2 & 6 & 6 & 4 & 2 & 2 & 2 & 1 \\
\hline & Mimosa caesalpiniifolia Benth. & & & & 1 & & 2 & 1 & & & \\
\hline & Myracrodruon urundeuva Allemão & & 1 & 1 & 2 & 3 & 2 & 4 & 4 & 1 & 2 \\
\hline & Spondias mombin L. & & & & & 2 & & & 1 & & \\
\hline & Tapirira guianensis Aubl. & & & & & & & & 1 & & \\
\hline \multirow[t]{6}{*}{ Annonaceae } & Annona coriacea Mart. & & & & 1 & 1 & & & & & 1 \\
\hline & Annona sp. & & & & 1 & & & & 1 & & 1 \\
\hline & Cardiopetalum sp. 1 & & & & & & & & & & 1 \\
\hline & Cardiopetalum sp. 2 & & & & & & & & & & 1 \\
\hline & Duguetia cf. marcgraviana Mart. & & & & 1 & & & & & & 1 \\
\hline & Xylopia aromatica (Lam.) Mart. & & & & 1 & 1 & & & 1 & & \\
\hline \multirow[t]{4}{*}{ Apocynaceae } & Aspidosperma sp. & & & & & 1 & & & & & \\
\hline & Aspidosperma subincanum Mart. & & & & & & & 1 & 1 & & \\
\hline & Hancornia speciosa Gomes & & & & 1 & & & & & & \\
\hline & $\begin{array}{l}\text { Himatanthus articulatus (Vahl) } \\
\text { Woodson }\end{array}$ & & & & & & 1 & & & & \\
\hline
\end{tabular}


Araliaceae Schefflera morototoni (Aubl.) Maguire et al.

Asteraceae Vernonanthura polyanthes (Sprengel) Vega \& Dematteis

Bignoniaceae Cybistax antisyphilitica (Mart.) Mart. Handroanthus impetiginosus (Mart. ex DC.) Mattos

Handroanthus ochraceus (Cham.)

Mattos

Handroanthus serratifolius (Vahl)

S.Grose

Jacaranda cuspidifolia Mart.

Tabebuia aurea (Silva Manso) Benth.

\& Hook.f. ex S.Moore

Tabebuia roseoalba (Ridl.) Sandwith

Bixaceae

Bixa orellana L.

Cochlospermum orinocense (Kunth)

\section{Steud.}

Burseraceae Tetragastris sp.

Trattinnickia rhoifolia Willd.

Calophyllaceae Calophyllum brasiliense Cambess.

Cannabaceae Trema micrantha (L.) Blume

Caryocaraceae Caryocar brasiliense Cambess.

Celastraceae

Hippocratea sp.

Maytenus gonoclada Mart.

Chrysobalanaceae Hirtella glandulosa Spreng. 
Clusiaceae

Combretaceae

Connaraceae

Dilleniaceae

Ebenaceae

Elaeocarpaceae

Euphorbiaceae

Fabaceae
Garcinia gardneriana (Planch. \& Triana) Zappi

Buchenavia macrophylla Eichler

Buchenavia tetraphylla (Aubl.)

R.A.Howard

Buchenavia tomentosa Eichler

Terminalia argentea Mart.

Connarus perrottetii (DC.) Planch.

Curatella americana $\mathrm{L}$.

Diospyros hispida A.DC.

Sloanea guianensis (Aubl.) Benth.

Luehea divaricata Mart. \& Zucc.

Mabea angustifolia Spruce ex Benth.

Mabea fistulifera Mart.

Mabea pohliana (Benth.) Müll. Arg.

Maprounea guianensis Aubl.

Adenanthera pavonina $\mathrm{L}$.

Anacardium occidentale $\mathrm{L}$.

Anadenanthera cf. colubrina (L.) Speg.

Anadenanthera cf. peregrina (Benth.)

Altschul

Andira cujabensis Benth.

Andira vermifuga (Mart.) Benth.

Apuleia leiocarpa (Vogel) J.F.Macbr.

Bauhinia rufa (Bong.) Steud.

Bauhinia sp. 1

Bauhinia sp. 2

$\begin{array}{lllll}7 & 2 & 2 & 1 & 1 \\ 4 & 1 & 1 & 1 & \\ 1 & & & & \\ & 3 & 1 & 3 & 1\end{array}$

3

(11

7

9

9

4

5

1

$\begin{array}{lllllll}1 & 1 & & & 1 & & \\ & 1 & & & & & \\ 7 & 3 & 5 & 4 & 4 & 3 & 3 \\ 4 & 5 & 4 & 4 & 3 & 1 & 1\end{array}$

$\begin{array}{lllllll}3 & 2 & 3 & 4 & 3 & & \\ 1 & & 1 & & & & \\ 1 & & & & & & 2 \\ 3 & 1 & 3 & 4 & & 1 & 1 \\ 3 & 3 & 5 & 3 & 4 & & \end{array}$


Bauhinia sp. 3

Bauhinia sp. 4

Bauhinia sp. 5

Bauhinia sp. 6

Bowdichia virgilioides Kunth

1

Chloroleucon mangense (Jacq.) Britton

\& Rose

Copaifera langsdorffii Desf.

Copaifera marginata Benth.

Dialium guianense (Aubl.) Sandwith

Dimorphandra mollis Benth.

Dipteryx alata Vogel

Dipteryx odorata (Aubl.) Willd.

Enterolobium maximum Ducke

Enterolobium schomburgkii (Benth.)

Benth.

Enterolobium timbouva Mart.

Hymenaea courbaril L.

Hymenaea martiana Hayne

Hymenaea stigonocarpa Mart. ex

Hayne

Inga heterophylla Willd.

Inga sp.

Inga thibaudiana DC.

Machaerium quinata (Aubl.) Sandwith

Ormosia excelsa Benth.

Physocalymma scaberrimum Pohl 
Samanea tubulosa (Benth.) Barneby \&

Humiriaceae

Humiriastrum dentatum (Casar.)

Cuatrec.

$\begin{array}{ll}\text { Hypericaceae } & \text { Vismia brasiliensis Choisy } \\ & \text { Vismia guianensis (Aubl.) Pers. } \\ \text { Lauraceae } & \text { Endlicheria } \mathrm{sp} . \\ & \text { Lauraceae - Indet } \\ & \text { Nectandra } \mathrm{sp} . \\ \text { Lythraceae } & \text { Parkia pendula (Willd.) Benth. ex } \\ & \text { Walp. }\end{array}$

Malpighiaceae

Byrsonima arthropoda A.Juss. J.W.Grimes

Senegalia mattogrossensis (Malme)

Seigler \& Ebinger

1

Senegalia polyphylla (DC.) Britton \&

Rose

Senna alata (L.) Roxb.

Senna silvestris (Vell.) H.S.Irwin \&

Barneby

Senna sp.

Stryphnodendron adstringens (Mart.)

Coville

Tachigali bracteosa (Harms) Zarucchi \& Pipoly

Tachigali vulgaris L.G.Silva \&

H.C.Lima

Vatairea macrocarpa (Benth.) Ducke

$3 \quad 1$

8

4

8


Byrsonima cf crispa A. Juss

Byrsonima cydoniifolia A.Juss.

Byrsonima intermedia A.Juss.

Byrsonima pachyphylla A.Juss.

Byrsonima verbascifolia (L.) DC.

Malpighia emarginata DC.

Malvaceae

Apeiba tibourbou Aubl.

Ceiba speciosa (A.St.-Hil.) Ravenna

Guazuma ulmifolia Lam.

Sterculia striata A.St.-Hil. \& Naudin

$\begin{array}{llllll} & & 4 & 2 & & 1 \\ 1 & 4 & 1 & 1 & 1 & 1 \\ & 1 & & 4 & 3 & 3 \\ & & & & & \\ 2 & 3 & 1 & 1 & & 2 \\ & & 1 & & & \\ 2 & 1 & 4 & 3 & 1 & 2 \\ & & & & 2 & 1\end{array}$

$\begin{array}{ll}\text { Melastomataceae } & \text { Miconia sp. } \\ \text { Meliaceae } & \text { Meliaceae - Indet }\end{array}$

1

Brosimum gaudichaudii Trécul

Moraceae

Machaerium acutifolium Vogel

Maclura tinctoria (L.) D.Don ex Steud.

Morus nigra L.

Pseudolmedia macrophylla Trécul

Pseudolmedia sp.

Myrtaceae Campomanesia eugenioides (Cambess.)

D.Legrand ex Landrum

Eugenia dysenterica (Mart.) DC.

Myrcia guianensis (Aubl.) DC.

Myrtaceae - Indet. 1

Myrtaceae - Indet. 2

Myrtaceae - Indet. 3

Myrtaceae - Indet. 4

Myrtaceae - Indet. 5 
Plathymenia reticulata Benth.

Psidium guajava L.

Indeterminada

Indet. 1

Indet. 2

Indet. 3

Indet. 4

Indet. 5

Indet. 6

Opiliaceae

Peraceae

Rubiaceae

Salicaceae

Sapindaceae

\& Hook. f.

Pera heteranthera (Schrank)

I.M.Johnst.

Alibertia edulis (Rich.) A.Rich.

Cordiera macrophylla (K.Schum.)

Kuntze

Cordiera sp.

Genipa americana L.

Rubiaceae - Indet.

Zanthoxylum rhoifolium Lam.

Casearia sp.

Cupania oblongifolia Mart.

Agonandra brasiliensis Miers ex Benth.

1

Cupania sp.

Magonia pubescens A.St.-Hil.

Matayba arborescens (Aubl.) Radlk.

Matayba guianensis

Matayba sp.

Sapindaceae - Indet. 
Sapotaceae

Simaroubaceae

Siparunaceae

Solanaceae

Urticaceae
Pouteria cf macrophylla (Lam.) Eyma

Simarouba amara Aubl.

Simarouba versicolor A.St.-Hil.

Siparuna guianensis Aubl.

Solanum lycocarpum A.St.-Hil.

Cecropia pachystachya Trécul

$\begin{array}{llllll}1 & 1 & 6 & 2 & 1 & 1 \\ 3 & 1 & 1 & 3 & 5 & 2 \\ 1 & & & & 1 & 2 \\ & 1 & & & & 1 \\ 1 & & & & 2 & 1\end{array}$

